\title{
The life course and subjective well-being across generations - an analysis based on cross-national surveys (2002-2016)
}

Hideko Matsuo ${ }^{1, *}$ and Koen Matthijs ${ }^{1}$

\section{Abstract}

This paper identifies subjective well-being trajectories through happiness measures as influenced by time, socio-economic, demographic and behavioural determinants. Hierarchical age-period-cohort models are applied to European Social Survey (2002-2016) data on the population aged 30 and older in 10 countries. A U-shaped relationship between age and happiness is found for some countries, but a rather flat pattern and considerable diversity beyond age 80 are detected for other countries. Lower happiness levels are found for baby boomers (1945-1964) than for preboomers and post-boomers, and also for late boomers (1955-1964) than for early boomers (1945-1954). Women, highly educated and native people are shown to have higher happiness levels than men, less educated and non-native people, respectively. Moreover, a positive assessment of income, having a partner, and being a parent, in good health, employed and socially active are all found to have a positive impact on happiness levels. We find evidence of gaps in happiness levels due to differences in socio-economic characteristics over the life course in some, but not in all of the countries analysed.

Keywords: subjective well-being; social inequalities; generations; healthy ageing

\section{Introduction}

Our life experience and overall well-being are central to our quality of life. Generally speaking, individuals with higher levels of life satisfaction have more positive emotional feelings and a higher quality of life (Skevington and Böhnke 2018). The recent OECD report 'How is life' (2020) - which takes a broader

\footnotetext{
${ }^{1}$ Center for Sociological Research, Research Unit Family and Population Studies (https://soc.kuleuven. be/ceso/fapos), Leuven, Belgium

${ }^{*}$ Correspondence to: Hideko Matsuo, Hideko.Matsuo@ kuleuven.be
} 
approach to assessing well-being, and takes into account multiple items in addition to subjective well-being, including income, health, the environment and social connections - shows that well-being has improved in many countries since 2010, when the financial crisis affected many OECD countries. However, the report also notes that less progress has been made in reducing income inequality, and that large gaps in well-being remain depending on gender, educational level and age. Quality of life is affected by demographic changes (e.g., increasing life expectancy, below-replacement fertility and international migration), growing inequality and social welfare programme constraints - and by the impact of these developments on intrinsic capacity ${ }^{1}$ and the environment ${ }^{2}$ (WHO 2015). In response to these trends, a number of studies - many of them policy-oriented have been carried out, including research on the development of preventive strategies for the disadvantaged and early assistance for those with urgent needs (Zaidi et al. 2017; UNECE/EC 2019). Healthy ageing $^{3}$ has therefore emerged as the leading global and EU policy framework (EC 2014; WHO 2015; OECD 2018).

Well-established approaches to the measurement of subjective well-being (SWB) already exist. These approaches usually involve examining levels of well-being for the overall population or sub-groups based on objective and/or subjective measures (Thompson and Marks 2008; Abdallah et al. 2011). Thus, levels of SWB or happiness emerge as core components of the multi-dimensional well-being concept. Levels of SWB (or happiness) are often described as following a U-shaped pattern over the life course (Helliwell et al. 2019): i.e., SWB starts at a higher level before age 20, declines slowly as people reach their mid-thirties, and then increases again after age 40. In reality, such patterns follow diverse age trajectories in different countries (Steptoe et al. 2015). This implies that more research is needed to generate more robust insights into this pattern. It has, for instance, been suggested that SWB should be measured using large-scale representative samples across countries and over time. Moreover, SWB is a multi-dimensional concept that is often measured through self-reported survey items. Much of the research on SWB has focused on its individual socio-economic and demographic determinants. Such studies have focused on individual countries or involved cross-national and/or cross-sectional analyses of one, several or all aspects of SWB (e.g., Diener 2009; Deeming 2013; OECD 2013; Helliwell et al. 2019).

Although these individual-level determinants of SWB have been studied extensively, relatively little is known about how SWB levels evolve over the life course;

\footnotetext{
1 This term refers to 'all the mental and physical capacities that a person can draw on and includes their ability to walk, think, see, hear and remember. The level of intrinsic capacity is influenced by a number of factors such as the presence of diseases, injuries and age-related changes' (WHO 2015, 28).

2 Environment is defined as 'the home, community and broader society, and all the factors within them such as the built environment, people and their relationships, attitudes and values, health and social policies, the systems that support them and the services that they implement' (ibid., 29).

3 Healthy ageing can be described as 'the process of developing and maintaining the functional ability that enables well-being in older age' (ibid., 28).
} 
about how SWB trends differ across birth cohorts; or about how SWB patterns differ across countries and regions. In other words, we currently lack a full comparative understanding of heterogeneous life course patterns of SWB with time trends.

Therefore, our aim in this paper is to contribute to the further development of SWB research by focusing on time trends and socio-economic and demographic determinants from a multiple-country, life course and cohort perspective. SWB is assessed through the 'people's level of happiness'. Individual-based, repeated cross-sectional data spanning more than a decade from the European Social Survey 2002-2016, which collects information on levels of happiness, are analysed by applying an extension of hierarchal age period cohort models (i.e., a modification of Bell and Jones 2015) to 10 individual countries. Two research questions are formulated: 1. What are the effects of different dimensions of time (age, period, cohort) on people's levels of happiness? 2. And, do we observe differences in people's happiness levels depending on their socio-economic, demographic and behavioural characteristics, controlled for time effects?

\section{General research background}

\subsection{Subjective well-being}

The Stiglitz report (2009), an influential document shaping European policy, defined the key dimensions of well-being as follows: material living standards, health, education, personal activities, social connections and relationships, the environment and economics, and the physical nature of insecurity. Well-being can be understood as people's subjective evaluations of their overall state of physical and mental health (OECD 2018). The concept of SWB constitutes the core of the multidimensional concept of well-being (Thompson and Marks 2008; Abdallah et al. 2011), which contains three sub-components: life evaluation, affect and eudemonia (Abdallah et al. 2011; OECD 2013). These sub-components overlap with empirical measures of SWB: hedonic and eudemonic. The former emphasises emotions and the evaluation of SWB through the pursuit of goals leading to happiness and life satisfaction; while the latter focuses on human flourishing, the fulfilment of one's potential in the form of individual autonomy and self-actualisation (Vanhoutte 2014).

The well-being of the ageing European population has been linked to "three main components: low probability of disease and disease-related disability, high cognitive and physical functional capacity, and active engagement with life' (Rowe and Kahn 1997, 433). It has been shown that individuals with higher levels of well-being tend to be more economically productive, and to have higher incomes, better health and higher life expectancy (Huppert 2009). The relationship between physical health and SWB is bidirectional: older people who are in poor health tend to experience 
lower levels of SWB, whereas having higher levels of SWB can contribute to better health (Steptoe et al. 2015).

\subsection{Time trends and the individual- and country-level characteristics of subjective well-being}

\subsubsection{Time trends}

Taking time trajectories into account is fundamental for understanding levels of SWB. There is extensive evidence indicating that age affects SWB. In an analysis of British panel data from 14 data collection waves starting in 1991 on respondents aged 16-64 years, Clark (2007) found a U-shaped relationship between age and SWB (i.e., overall mental well-being, overall life satisfaction). A U-shaped ageSWB relationship has also been confirmed for other countries: Blanchflower and Oswald (2008) found evidence of the existence of such a pattern for the US and Western Europe between 1976 and 2006 based on data from the US General Social Survey (1972-2006), the Eurobarometer survey (1976-2002) and the World Values Survey (1981-2004) covering respondents aged 20 and older in 80 countries. A U-shaped pattern was also observed for Eastern European, Latin American and Asian nations, but not for some developing countries. More recently, Blanchflower (2021) re-examined this U-shaped happiness-age curve globally based on recent data for 145 nations, including 109 developing countries. After controlling for sociodemographic variables and analysing samples covering respondents under age 70, a U-shaped pattern was confirmed globally.

The existence of such a relationship may seem counterintuitive, as the elderly are more likely than younger people to experience negative life events, such as reduced income, deteriorating health or the death of a partner. This pattern has been explained through socioemotional selectivity theory (Carstensen et al. 2003), which argues that compared to younger people, the elderly pay more attention to emotional goals and experiences, and are more likely to remember emotional and positive information.

It appears, however, that this U-shaped curve is not universal. Frijters and Beatton (2012) rejected the claim that there is a U-shaped relationship between age and life satisfaction (i.e., individual happiness) based on an analysis of panel survey data for respondents aged 18 and older in Germany, the United Kingdom and Australia. When using conventional regressions of fixed-effects models, the U-shaped relation disappears due to reverse causality. They argued that 'happinessincreasing variables, like getting a job, a high income, and getting married, appear to happen mostly to middle-aged individuals who were already happy' (ibid., 540). There is other evidence that the U-shaped curve does not exist across all countries. Based on the results of a Gallup poll among people aged 15 in 160 countries, Steptoe et al. (2015) examined the relationship between age and three aspects of SWB (i.e., evaluative, hedonic and eudemonic). They found a U-shaped relationship 
in high-income and English-speaking countries, but a negative association in other regions, including former Soviet states and Eastern Europe.

Levels of SWB also appear to be determined in part by people's birth cohort. Empirical evidence from the US generally shows that levels of SWB are lower among baby boomers than among members of earlier birth cohorts, keeping other factors constant; even though selection effects exist (Yang 2008). Based on data from the English Longitudinal Study of Ageing (ELSA), Jivraj et al. (2014) found that, after controlling for age, older cohorts (aged 70+ in 2002-2011; i.e., pre-baby boomers) had the same or higher levels of SWB (i.e., quality of life, depressive symptomatology, life satisfaction) than younger cohorts (aged 50-59 in 2002-2011; i.e., late baby boomers).

There are many reasons why baby boomers might be distinct from members of other cohorts. The share of elderly in the population is currently growing primarily because the baby boom cohorts (i.e., cohorts born in 1945-1964) are so large. Baby boomers have a socio-economic and cultural identity related to their educational and occupational careers that is distinct from the identities of the previous and the following generations. Compared to the preceding generation, baby boomers have tended to report lower levels of well-being, which can likely be attributed to their early and formative life conditions and experiences, including being faced with rising economic inequality in the post-war era resulting from a larger cohort size that created greater competition for education and jobs (Easterlin et al. 1993; Fukuda 2013). Moreover, at least in Western countries, baby boomers can be seen as the forerunners in the dramatic changes in family life that characterised the Second Demographic Transition (SDT) regime (Lesthaeghe 2014). Based on data from three US censuses conducted between 1980 and 2000, Lin and Brown (2012) found that one out of every three baby boomers was unmarried, largely due to divorce or having never married, with a very small proportion having been widowed. Baby boomers continue to experience unstable marriages as rates of divorce increase in later life, as part of the so-called 'grey divorce' trend (Brown and Wright 2017; Stepler 2017).

While baby boomers as a group differ from other cohorts in terms of their socioeconomic, cultural and demographic characteristics, considerable heterogeneity can also be found within the group of the baby boomers (i.e., early boomers were born in 1945-1954 and late boomers were born in 1955-1964). Based on the 'Midlife in the U.S.' surveys of 1995-1996 and 2004-2006, Barrett and Toothman (2014) examined the subjective experiences of ageing and their health consequences (i.e., individual views of the life course, such as the structure, timing and advancement of careers) during the midlife period. The early boomers reported having significantly more youthful identities and later boundaries for middle age than the late boomers. The late baby boomers also had lower socio-economic positions than the early baby boomers, keeping age constant. These findings imply that the early and the late boomers have experienced different economic and social conditions that have produced different life course trajectories (ibid.).

While age and cohort effects are rather well-established, evidence on the impact of historical events or trends on levels of SWB has been rather mixed. While economic 
prosperity has increased over time, happiness has not risen in a linear manner (Easterlin 2010). This non-linear relationship between income and happiness over time has also been documented by Yang (2008). An analysis of General Social Survey (GSS) data showed that happiness levels decreased in the 1970s-1980s, and gradually rebounded thereafter. However, Ortiz-Ospina and Roser (2017) provided another perspective. Based on an analysis of data from the Gallup World Poll and the World Values Survey, they found evidence that happiness has increased globally over the past three decades (1984-2014). In the same study, and based on data from the Eurobarometer survey on life satisfaction, the authors also reported observing fluctuations across historical periods (1973-2016). However, they generally found decade-long positive trends for most European countries except Greece, where there was a substantial decrease in life satisfaction during the financial crisis (2007-2012).

\subsubsection{Individual socio-economic, demographic and behavioural differences in SWB levels, and time variations}

Levels of SWB are highly dependent on people's socio-economic and demographic characteristics. Multi-dimensional concepts and theoretical frameworks can provide valuable insights into this relationship by highlighting a number of determinants of SWB, such as income, health, social contacts, employment status, personality and culture (religion) (OECD 2013, 33, Figure 1.1); as well as marital status, education and living arrangements (Thompson and Marks 2008). These social differentials of SWB levels are also strongly associated with the individual's place of origin (OECD 2017).

Clear evidence exists on the effects of socio-economic position on levels of SWB. According to a systematic review of literature from the 1995-2013 period, among the population aged $60+$, having a poor socio-economic position (as reflected in, for example, levels of education, income, wealth, financial assets, social class and neighbourhood characteristics) is associated strongly with poor SWB (i.e., subjective health, life satisfaction, quality of life, well-being), whereas this association weakens when mediated by social support and a positive self-perception of health (Read et al. 2016). A significant positive relationship has been found between SWB (i.e., happiness, life satisfaction, morale) and levels of education in particular (Witter et al. 1984). However, while there is strong evidence that higher education leads to greater happiness, either directly or indirectly (e.g., via income), this relationship is complex due to the difficulties that can arise in the operationalisation of education (Michalos 2008).

Empirical research has identified gaps in levels of SWB between native and non-native people, even after controlling for country and individual characteristics (Hadjar and Backes 2013). Migrant populations account for around 10\% of Europe's total population, although the proportions and socio-economic backgrounds of these migrant groups differ substantially across countries. Based on an analysis of data from the Survey of Health, Aging and Retirement in Europe (SHARE), Sand and 
Gruber (2018) presented empirical evidence indicating that non-European migrants and migrants from Southern and Eastern Europe have substantially lower levels of SWB than natives. They also found, however, that migrants from Northern and Central European countries have levels of SWB comparable to those of nonmigrants. In general, migrants have been shown to have lower socio-economic status and SWB levels than the native population. However more empirical evidence of this general finding is required because of the significant methodological issues in this research related to non-response and measurement errors (OECD 2017).

An earlier study has provided evidence of gaps in levels of SWB by gender, albeit with large differences by country (Inglehart 2002). The analysis of data from the World Values Survey in 65 countries between 1980 and 1999 using a life satisfaction measure found that women had higher levels of SWB than men in the more developed countries. However, it appears that gender can have mixed effects. On the one hand, based on a meta-analysis of developmental and gerontological literature obtained through electronic databases (i.e., PSYCINFO, MEDLINE, PSYINDEX), Pinquart and Sörensen (2000) found that associations between socio-economic status (e.g., education, income and social class) and SWB levels (i.e., life satisfaction, happiness, self-esteem) were generally stronger for men than for women. The authors attributed this finding to men having a traditional occupational path focused on personal career development. Another view has been provided by Witter and others (1984). Based on a meta-analysis of US literature prior to 1980, they found a significant positive relationship between education and SWB levels that was stronger for women than for men. The authors noted, however, that the strength of the relationship was reduced when occupational status was controlled for in the model.

What is less clear is how these differences in levels of SWB by socio-economic characteristics described above vary over the life course. On the one hand, cumulative advantage and disadvantage theory argues that socio-economic gradients in SWB levels can vary over the life course (Dannefer 2003). This implies that relatively small differences in education or income during adulthood can widen during the life course. It has, for example, been shown that there is a strong negative relationship between financial distress and well-being (i.e., control autonomy, selfrealisation, pleasure) that widens in old age (Niedzwiedz et al. 2015). Interestingly, this study found that this association is weaker for Northern countries.

On the other hand, a number of studies have shown that SWB levels tend to converge over the life course. For example, a study for the US found that having advantageous socio-economic characteristics (e.g., being male, white and highly educated) does not continue to confer advantages at older ages (Yang 2008). Sand and Gruber (2018) also found evidence that the gap in levels of SWB between natives and migrants diminishes at older ages. Another study by Inglehart (2002) found that in rich Western societies - but not in many non-Western (Asian, Latin American, African) societies - the relationship between gender and well-being reverses, from women having an advantage at younger ages to women having a disadvantage at older ages. Gender differences in SWB (i.e., life satisfaction, 
happiness) have been attributed to women generally reporting higher frequencies of depression because of their disadvantaged socio-economic position (Van de Velde et al. 2010), and experiencing and expressing emotion more than men (Plant et al. 2004).

Research has shown that demographic factors play an important role in SWB levels (and the reverse). Lower levels of SWB, measured in a multi-dimensional manner (i.e., life satisfaction, emotional well-being, vitality), were found for divorced than for married people in Northern Belgium (Jenkinson et al. 2020). The relationship between fertility and SWB has been studied extensively, mostly in North America and Europe. An analysis of data from the British Household Panel Survey found that having children has large positive effects on life satisfaction (Angeles 2010), and that these effects become stronger as the number of children increases. Recent cross-national research has shown that high levels of life satisfaction instigate fertility, even in low-fertility countries (Mencarini et al. 2018), although this relationship can vary depending on individual factors and across institutional contexts. Based on data from a large number of OECD countries, Glass and others (2016) found large variations in the happiness of parents, depending on the generosity of family policies. There is evidence that the association between parenthood and SWB can be weakened or strengthened depending on cultural practices and institutional arrangements, in particular when gender inequality is present (Aassve et al. 2015). Thus, the generally positive relationship between the number of children and happiness can be influenced by contextual factors that lead to happiness levels being higher at younger ages (i.e., around the birth of first child), but decreasing thereafter (Myrskylä and Margolis 2014). Moreover, it has been shown that life-cycle conditions can affect the relationship between happiness and fertility due to the financial and emotional costs of childrearing, but that the high costs for parents when children are young can be compensated when the children are older and provide their parents with social protection (Margolis and Myrskylä 2011).

\subsubsection{Country institutional characteristics and individual subjective well-being}

In an analysis of the World Database of Happiness that controlled for individual factors, including income, unemployment, inequality, social capital and life satisfaction, Spruk and Kešeljević (2016) found that countries with better economic institutions and higher levels of economic freedom (e.g., property rights, open markets, limited governance) have higher individual happiness levels. Based on data from the World Values Surveys in OECD countries, Welsch and Kühling (2016) found evidence of a positive relationship between macro-economic performance and life satisfaction levels, with trade openness and institutional quality playing a crucial role. Rather than mediating effects, Pacek and Radcliff (2008) found that welfare programmes have direct effects on individual happiness and life satisfaction. 
These findings imply that a country's social welfare characteristics also have an effect on individual well-being levels.

\subsection{Study framework, research questions and general hypotheses}

\subsubsection{Study framework}

In order to examine SWB empirically, this paper focuses from a life course perspective (Giele and Elder 1998; Shanahan et al. 2016) on one aspect of SWB, happiness. Specifically, we examine the time, socio-economic, demographic and behavioural determinants of happiness. The framework comprises four life course components 'individual agency', 'linked lives', 'historical period and time' and 'timing' - that correspond broadly to age, period and cohort. Our study focuses in particular on age and cohort. Cohort is an important concept for understanding social change because each cohort has distinct experiences and characteristics, driven by the changing contexts of formal education, socialisation and historical events (Ryder 1965). Compared to other generations, the baby boomers experienced higher levels of competition in schools and jobs, which resulted in socio-economic and demographic differentials in education, income, family and health status.

Over the life course, gaps in levels of SWB by socio-economic characteristics can either increase or decrease. On the one hand, cumulative advantage and disadvantage theory argues that relatively small differences that emerge during adulthood can widen during the remainder of the life course. These relative advantages and/or disadvantages can result in widening differences in later life (Dannefer 2003). For instance, even though in the post-war period overall educational levels increased and the welfare state expanded, having low educational attainment early in life continued to affect people's subsequent occupational trajectories, resulting in economic hardship even after retirement (Oris et al. 2017) that could influence their SWB levels. On the other hand, there may be age effects of happiness, which suggests that socially advantaged groups are not necessarily better off than the advantaged groups later in life. This implies that crossovers or smaller gaps in SWB levels by socio-economic gradients can occur during the life course, resulting in converging SWB levels.

\subsubsection{Research questions and hypotheses}

Two research questions, and corresponding hypotheses, are formulated as follows.

1. What are the effects of different dimensions of time (age, period, cohort) on people's levels of happiness? Following previous empirical research on the impact of age, we expect (H1a) to observe a general U-shaped pattern. (H1b) We also assume that the cohort effects (i.e., effects resulting from changes that occur and influence people in their earlier years) are more substantial than the period effects (i.e., effects resulting from changes that influence all age groups equally). 
This means that we anticipate finding some negative period effects for the years of the economic-financial crisis (2008 and later), and that we expect to observe more substantial negative effects for baby boomers, and particularly for late baby boomers (born in 1955-1964) relative to pre-baby boomers (born before 1945). (H1c) These time-specific trends are, however, assumed to differ cross-nationally: we expect to find U-shaped age effects in Northern and Western European countries, but smaller effects in Eastern European countries; and lower levels of happiness in Eastern European countries than in Northern and Western European countries.

2. Do we observe differences in happiness levels depending on people's socio-economic, demographic and behavioural characteristics, controlled for time effects? And, if so, do we observe widening or decreasing differences in people's happiness levels over time? (H2a) We assume that people with weaker socioeconomic profiles have lower levels of happiness in general, but that these patterns are diverse during the life course, and to some extent across cohorts: i.e., we expect to find that some socio-economic profiles (e.g., low education) exhibit growing disparities; and that others (e.g., female, non-native) show crossover trends whereby socio-economic advantages turn into disadvantages, and vice versa. (H2b) We also expect to observe lower happiness levels among people with lower socio-economic and non-traditional family status; albeit with substantial cross-national differences, as discussed above. We furthermore expect socio-economic gaps due to gender and educational level to decrease moderately in Northern and Western European countries because of the effects of general social welfare programmes, but to remain large in Eastern and Southern European countries, where social welfare programmes are rather limited. While non-native status is largely related to the socio-economic characteristics and country origin of the migrants in each country, decreasing nativenon-native gaps are generally anticipated.

\section{Data, measures, methods}

\subsection{Data}

The data files of ESS Rounds 1 to 8 (2002-2016), ${ }^{4}$ and in particular the subsample data file on non-institutionalised individuals (i.e., those not residing in institutions) aged 30-100 in 10 countries (DE, ES, GB, HU, IE, NL, NO, PT, SE, SI), were analysed. ESS is a repeated cross-sectional and multi-country survey, with a comparable European sample. It aims to ensure high methodological quality with respect to survey design and measurement for cross-national analysis. The cumulative datasets include 15 countries for all rounds, which means that five

\footnotetext{
4 This analysis makes use of the most recent publicly released cumulative ESS data file on version 6.6 (edition of 12 December 2018, European Social Survey 2018). This version consists of 15 countries (BE, CH, DE, ES, FI, GB, FR, HU, IE, NL, NO, PL, PT, SE, SI).
} 
countries were removed from the analysis for the purposes of this paper. ${ }^{5}$ The total number of sample units analysed for 10 countries was 120,810 units, as only sample units with complete cases were included in our analysis. Missing data accounted for less than $3 \%$ of the sample in each country.

\subsection{Measures}

Measures were selected and conceptualised based on Yang (2008), Bell (2014) and Bell and Jones (2015), taking into consideration other empirical research, as discussed in Section 2. All measures selected were collected in each round of ESS.

\subsubsection{Individual-level dependent variable}

We operationalised the hedonic aspect of SWB through measures of happiness, and created an ordinal response variable ( $1=$ very happy, $2=$ happy, $3=$ unhappy) based on an originally 11-point scale variable (i.e., how happy are you?; 0 : extremely unhappy to 10 : extremely happy). The ordinal response variable ranges from $1=$ very happy (original points scale of $8,9,10$ ), over $2=$ happy (original points scale of $5,6,7$ ) to $3=$ not too happy (original points scale of less than 4). We chose to use an ordinal response variable because we observed that there were few responses for some of the response choices for the continuous variable. This was considered a major disadvantage in the application of crossnational analysis.

\subsubsection{Individual-level independent variables}

Key socio-economic individual items - age, birth year, gender, level of educational attainment and native/non-native status - were included in the fixed part of the initial model. These variables were mostly transformed into dummies, except for age and birth year, which were grand mean centred and squared. In addition, the interaction effects between these socio-economic variables and time (i.e., age and birth year) were included in the extended models (models 2,3 ). The interaction effects between age and birth year that test for life course trends were incorporated in order to examine varying cohort effects (Bell 2014; Bell and Jones 2015). This item made it possible to assess whether and how life course trajectories change across cohorts. In addition to the above, the respondent's assessment of income, employment status,

\footnotetext{
5 Five countries are removed from the analysis due to the use of a non-standardised questionnaire on partnership status across rounds in Finland and France; and because no values for covariate parameters were obtained in the random models in Belgium, Poland and Switzerland due to insufficient sample sizes in the sub-groups. However, all of the geographical regions of Europe are represented by at least one of the 10 countries remaining in the analysis.
} 
partnership status, child status, health condition and social interaction level were all included in the full model.

- Age at the time of the survey and polynomial age

- Birth year and polynomial birth year

- $\operatorname{Gender}(1=$ female; 0 = male $)$

- Years of education: low [ $1=$ below 12 years; $0=$ otherwise); high $[1=$ more than 16 years; $0=$ otherwise]

- Non-native status $\left(1=\right.$ self and/or parents not born in country; $0=$ otherwise $^{6}$

- Feeling about current household income $(1=$ difficult to manage; $0=$ otherwise)

- Current partnership status $(1=$ divorced or separated; $0=$ otherwise $) ;(1=$ widowed; $0=$ otherwise) $(1=$ never married; $0=$ otherwise $)$

- Current child status $[1=$ have child/ren (i.e., either non-residential and/or residential child; $0=$ otherwise)]

- Current employment status $(1=$ part-time work; $0=$ otherwise $), \quad(1=$ unemployed; $0=$ otherwise $),(1=$ retired; $0=$ otherwise $)$

- Self-perception of health condition $(1=$ excellent; $0=$ otherwise $),(1=$ fair; $0=$ otherwise $),(1=$ poor; $0=$ otherwise $)$

- Social interaction [take part in social activities compared to others of same age: 1 (much less than most) to 5 (much more than most)]

- Interaction of, respectively, gender, education and native/non-native status with age

- Interaction of, respectively, gender, education and native/non-native status with birth year

- Age interacting with birth year

\subsubsection{Random level variables}

Period (survey rounds) and cohort groups (10-year groups) were included in the random part of the hierarchical model. In each survey round, data collection took place in the same year in all countries (European Social Survey 2016).

\footnotetext{
6 The country of birth of the respondent and of both parents are taken into account in determining the respondent's non-native/native status. This means, for instance, that second-generation (children of first-generation migrants who were born in another country) respondents are considered non-native in our analysis.
} 


\subsection{Methods}

\subsubsection{Descriptive analysis}

Profiles of high happiness levels are shown first, distinguished by periods and birth cohorts in each country. Each survey round (eight rounds corresponding to 20022016) and each cohort group (comprising 10 years, corresponding to birth years between 1905 and 1985) are shown.

\section{Analytical models}

Hierarchical age-period-cohort (HAPC) models applying Bell and Jones's modifications are used (Snijders and Bosker 1999; Yang and Land 2013; Bell 2014; Bell and Jones 2013, 2015) to examine the dynamic changes in SWB levels through happiness measures by time trends. Cohort effects, which result from events and experiences that occur and influence people in the earlier years of their life course, are considered more substantial than period effects, which result from general historical events that influence all age groups equally. This assumption is justified because it enables us to take into account the upbringing and experiences of particular cohorts by examining pre- and post-baby boomers' levels of happiness.

In order to address the linearly dependent issue when modelling age, period and cohort, our model constrains the period linear trends to zero by including the birth year as a linear fixed effect (Bell 2014; Bell and Jones 2015). Basic level-1 consists of (Yang and Land 2013; Bell and Jones 2015, 203):

$$
\operatorname{Pr}\left(\text { Happy }_{i\left(j_{1} j_{2}\right)}=1\right)=\beta_{0 j_{1} j_{2}}+\beta_{1} A g e_{i\left(j_{1} j_{2}\right)}+\beta_{2} A g e_{i\left(j_{1} j_{2}\right)}^{2}+\mathrm{e}_{i\left(j_{1} j_{2}\right)}
$$

The random intercept model is:

$$
\beta_{0 j_{1} j_{2}}=\beta_{0}+\beta_{3} \text { Cohort }_{j_{1}}+u_{j_{1}}+u_{j_{2}}
$$

The dependent variable is the ordinal response outcome of happiness of the $i$ th respondent in the $j_{1}$ th period (survey rounds) $\left(j_{1}=1-8\right)$ and the $j_{2}$ th cohort $\left(j_{2}=1-9\right)$ (ibid. 203). The addition of a single birth year (cohort) in the fixed level is a modification by Bell (2014) and Bell and Jones (2015) of the model proposed by Yang and Land (2013). Period and cohort residuals remain in the model to illustrate contextual effects. Based on the combined 2-level models, the likelihood of 'being very happy' is predicted. The model includes gender (female/not), migrant status (native origin/not) and levels (low/high) of educational attainment; the interaction effects between those variables and age/birth year; and socio-economic, demographic and behavioural items (e.g., partnership status, child status, employment status, health status, income assessment, social interaction levels).

Happiness levels are estimated with three models for each country using the SAS programme and implementing proc glimmix. All models consist of individual fixed 
and random parts. The basic model consists of time and individual fixed core socioeconomic determinants (model 1), to which interaction effects are added (model 2), followed by additional socio-economic, demographic and behavioural determinants (model 3). Time trends are examined by studying the statistical significance of individual estimated coefficients for birth cohorts and periods that identify patterns in graphs, as proposed by Frenk and others (2013). Models are estimated with the hierarchical ordinal logit models of happiness using residual pseudo-likelihood estimation. Fit statistics (i.e., -2 Res Long Pseudo-likelihood) are documented and examined across models. All model results incorporate design weights, which are publicly available in datasets.

\section{Results}

The overall picture of the levels of happiness is presented first, in the form of descriptive trends. The core socio-economic determinants controlled by time are then shown, followed by varying happiness levels by core socio-economic characteristics over the life course and across birth cohorts, as well as additional covariates. All results are distinguished by countries, and are presented in the respective tables and figures.

\subsection{Descriptive statistics}

Table 1 presents the characteristics of the sample average for each country individually and for all countries together. Across all countries, the mean age is 54 years. Slightly more women (53\%) than men are included in the sample. Most individuals are native (10\% are non-native). The respondents' educational backgrounds are diverse: on average, the share of those with fewer years of schooling ( $<12$ years) is $46 \%$, and the share of those with more years of schooling (+16 years) is about $23 \%$. On average, $10 \%$ of respondents are divorced and widowed, and $17 \%$ are never married. A majority of individuals (roughly $81 \%$ ) have children. More than one-fifth of respondents assess their household income negatively. More than one-quarter of respondents are retired (28\%), whereas around 10\% work part-time and 5\% are unemployed. On average, $28 \%$ of respondents rate their health status as fair, while $10 \%$ assess it as poor. These general sample characteristics of the 10 countries combined are, however, subject to substantial cross-national differences, as shown by several measures for each country in Table 1 . There are particularly large differences with respect to educational levels, assessments of income and selfreported health levels.

Classified by period and cohort, the proportion of people with high levels of happiness differs across countries (Figure 1). For Western and Northern European countries, relatively similar high shares are observed (50-80\% of each birth cohort), whereas the shares are generally lower for Southern (PT) and Eastern European 


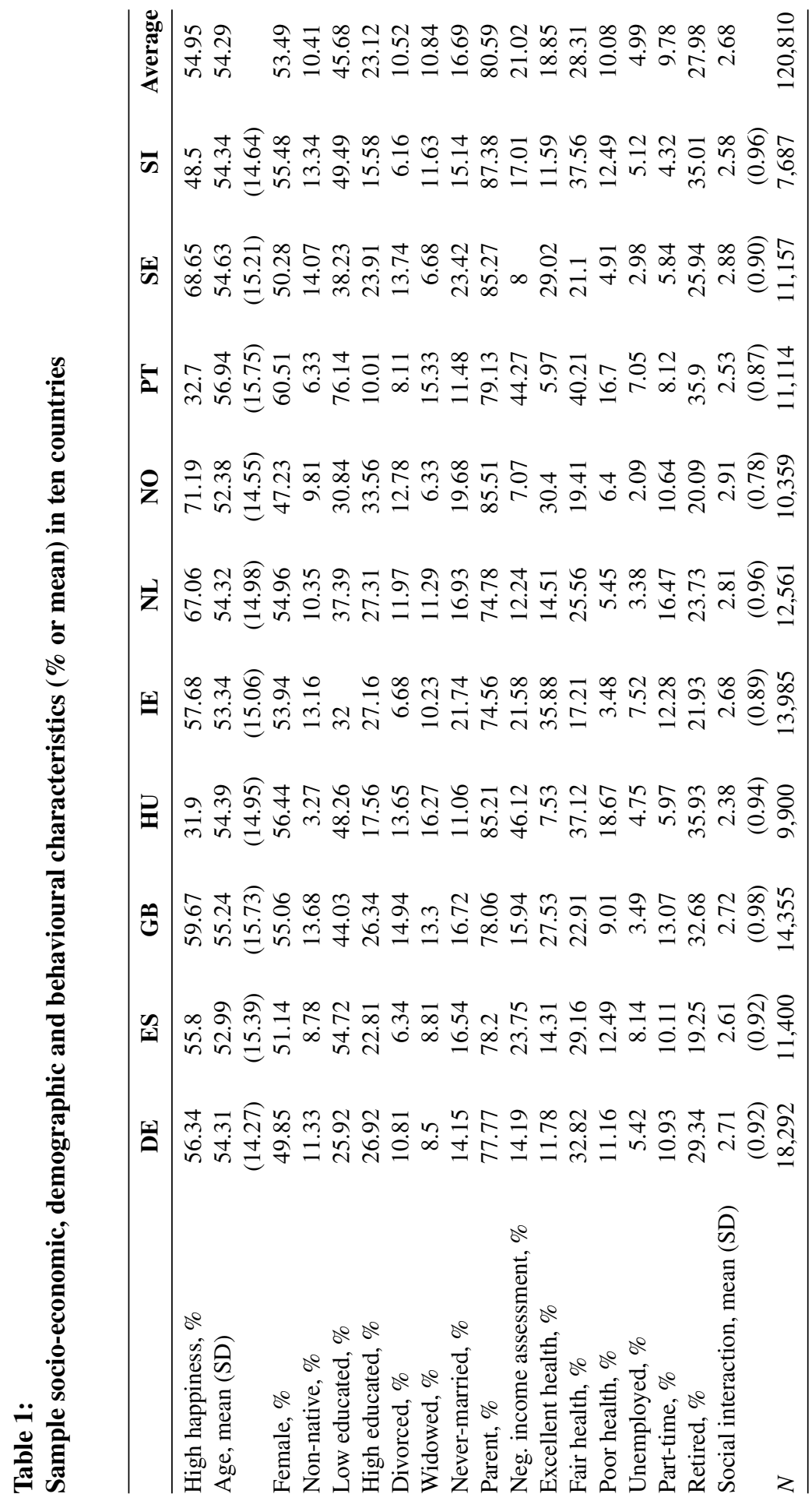


(HU, SI) countries (below 60\% for each birth cohort). For the latter group of countries, the more recent the cohort, the higher the proportion, which leads to a positive linear trend. High percentages of 'very happy' people are also found to some extent across different periods for several countries (DE, IE, PT). The low share for Portugal in the 2010-2012 period stands out.

\subsection{Time trends}

Starting with the analysis of age effects, a key question is whether life really begins after people have made it through their forties, as formative years of struggle

\section{Figure 1:}

Proportion high happiness (very happy) by birth cohort (1905-'85) and survey rounds (2002-16) in ten countries
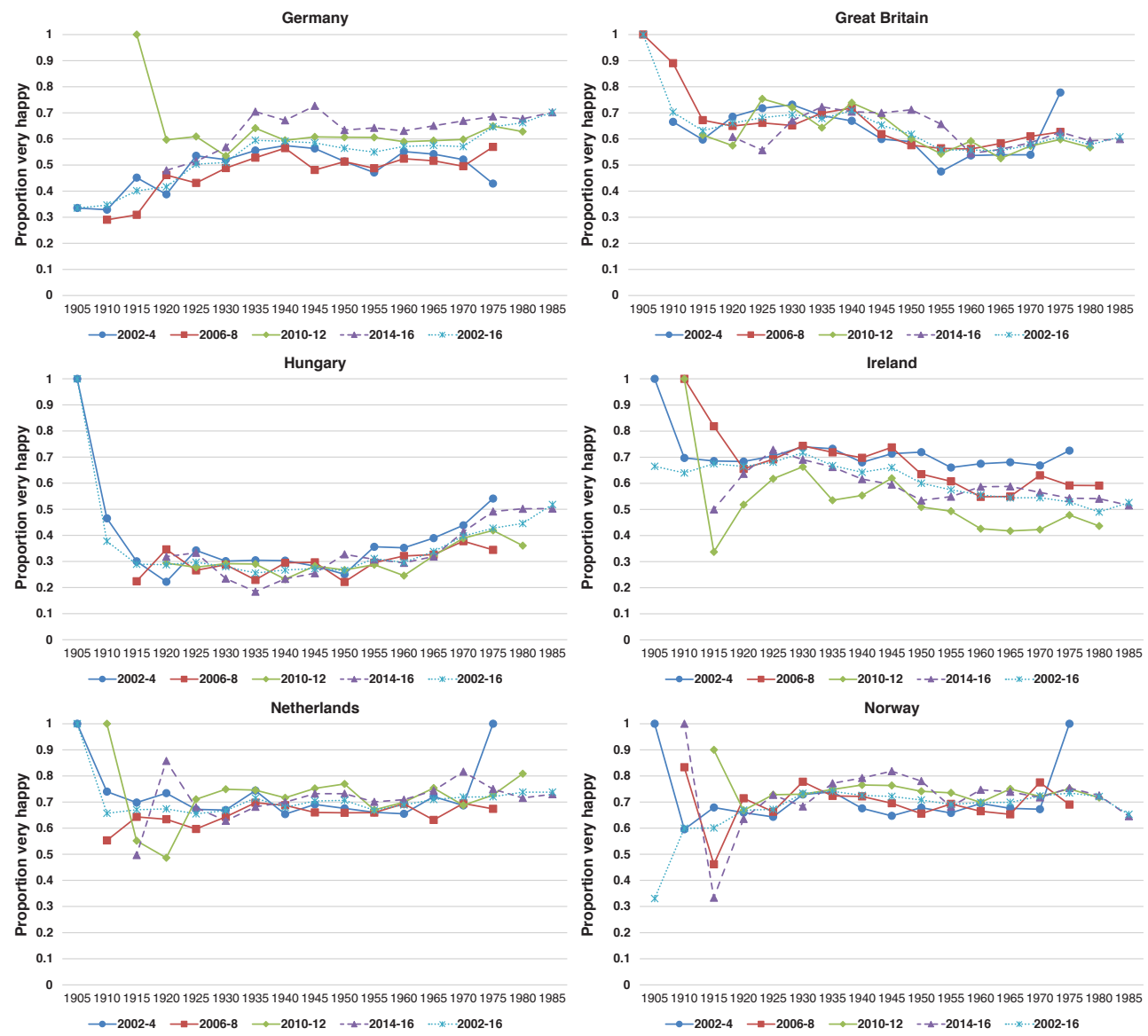


\section{Figure 1:}

\section{Continued}
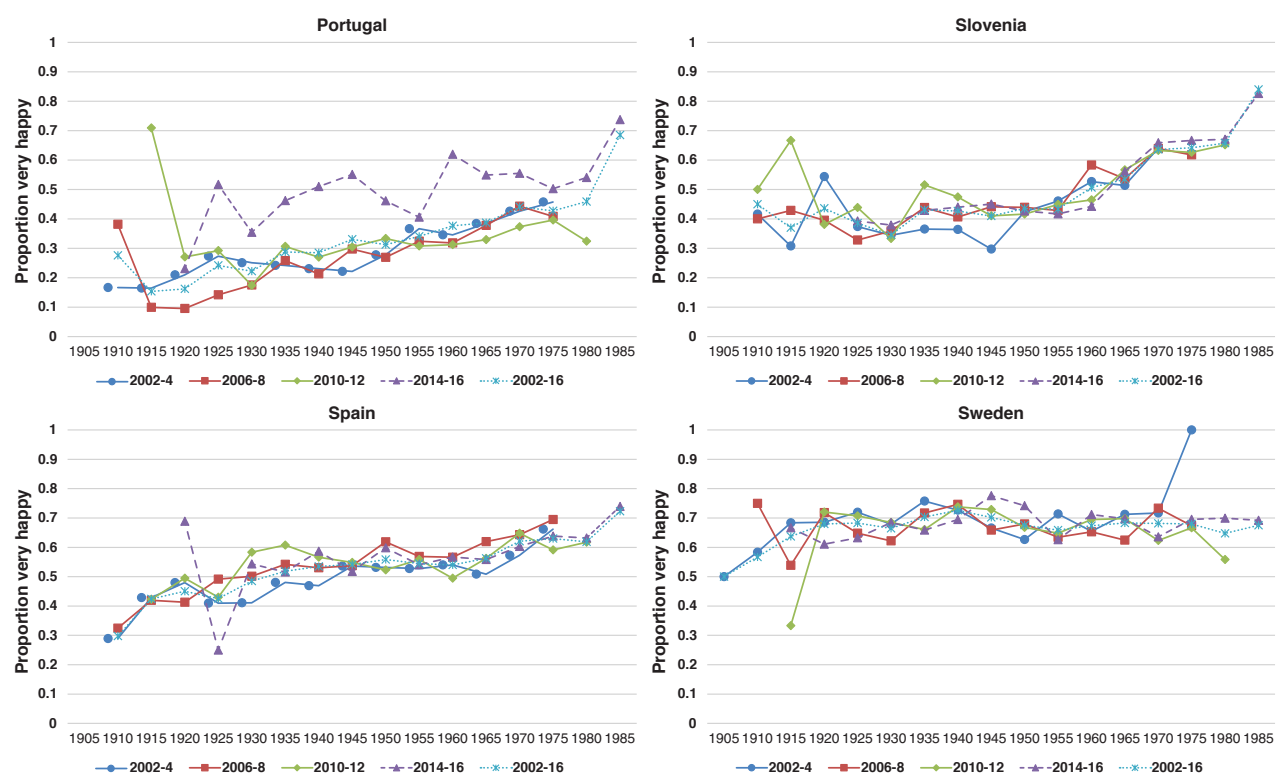

Note: This category of 'very happy' corresponds to the dichotomization of response items in the model. Source: European Social Survey cumulative data file in 10 countries.

and challenges are compensated for with lower stress and higher income levels, especially as children start leaving the parental home. Thus, a period of happiness could begin from the mid-fifties onwards. Figure 2 shows the overall age trends for the predicted probabilities of being very happy estimated from model (1) presented in Table 2. ${ }^{7}$ The fixed effects of age and polynomial age in Table 2 do not show significant effects in all countries, although Figure 2 clearly displays age trends by country. This figure shows that happiness evolves, but differently across countries. A U-shaped relationship between age and happiness (i.e., reflecting lower levels of happiness in mid-life, which increase thereafter) is found in several countries (GB, HU, SI) (H1a), while other countries (DE, ES, IE, NL) show rather flat age patterns until ages 60-70 (i.e., younger seniors). A general decline with age, and negative age effects for older seniors (i.e., ages $80+$ ), are observed for Southern European countries (PT). Contrary to expectations (H1c), a non-U-shaped pattern is not observed among Eastern European countries (HU, SI), whereas two Southern

\footnotetext{
7 The predicted logits (denoted $\beta$ ) are converted to predicted probabilities by calculating probability = $1 /(1+\exp \beta)$.
} 
European countries (ES and PT) exhibit this pattern. These different age trends across countries may be due to different reasons, one of which may relate to the sample selection, as the proportion of very old people varies substantially across countries.

\section{Figure 2:}

Overall age trends for predicted probabilities of being very happy based on model 1 in ten countries
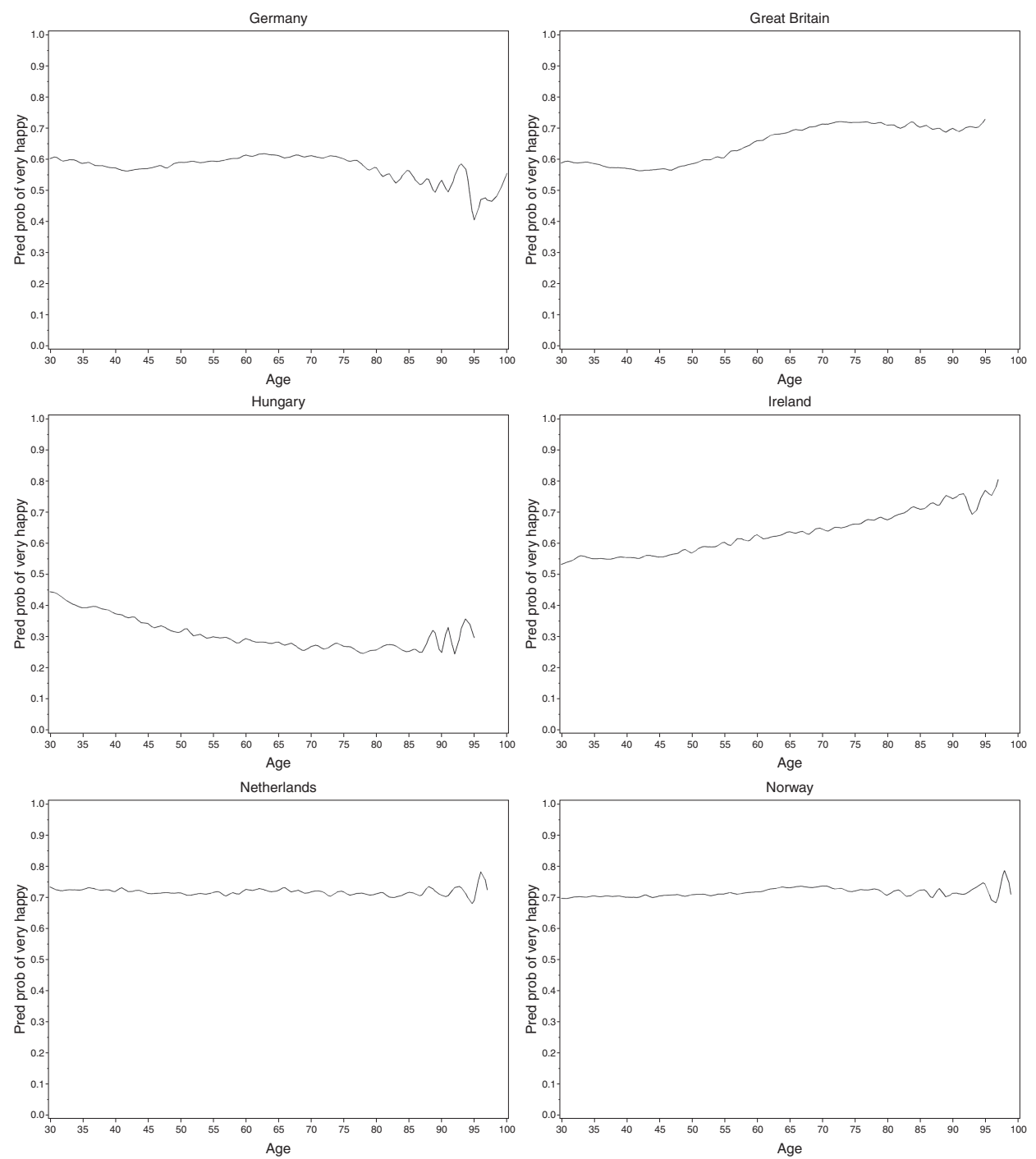
Figure 2:

\section{Continued}
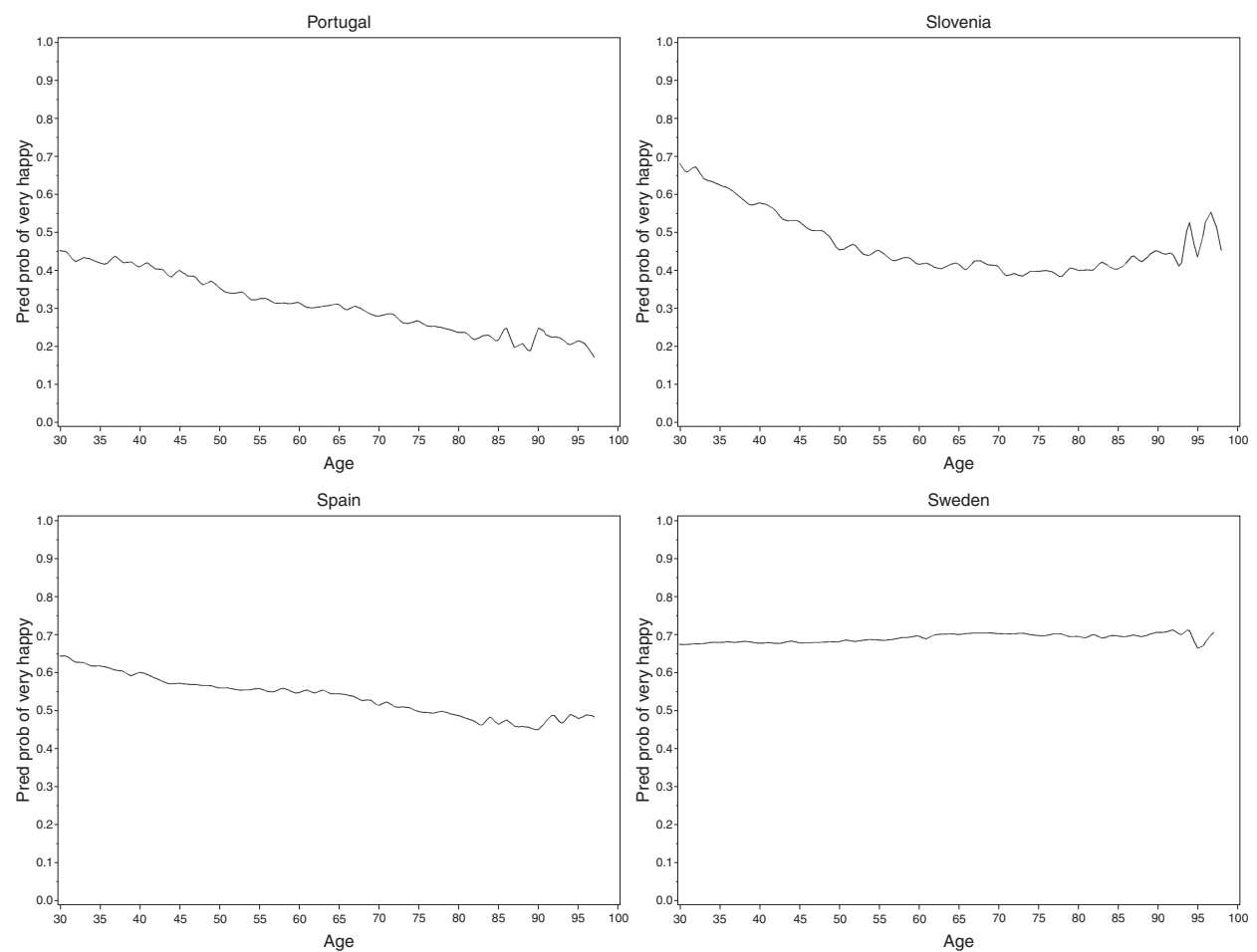

Both period and cohort effects on happiness levels are shown in Figure $3^{8}$ based on model 1. We examine period and cohort residuals through the coefficients for each period and cohort level in order to examine individual estimated period and cohort effects (Frenk et al. 2013). The corresponding figures in each country graphically plot the estimated cohorts and time period effects within the $95 \%$ confidence bounds. The coefficients of the period and cohort residuals are, in general, not large, although period and cohort variations are observed. In line with our hypothesis $(\mathrm{H} 1 \mathrm{~b})$ and previous empirical research on cohort characteristics (Barrett and Toothman 2014), we find relatively low levels of happiness among baby boomers. In contrast to pre-baby boomers (i.e., those born before 1945), baby boomers in most countries have lower levels of happiness compared to the average values across all cohorts in each country. Moreover, in most countries, we find that late baby boomers (i.e., those born in 1955-1964) have lower levels of happiness

8 Following Frenk and others (2013), time trends are examined by studying the statistical significance of individual estimated coefficients for birth cohorts and periods, and identifying patterns in graphs. 
Table 2:

Effects on high levels of happiness: Age-period-cohort models 1-3 in ten countries

\begin{tabular}{|c|c|c|c|c|}
\hline \multirow[b]{3}{*}{ Intercept } & \multicolumn{4}{|c|}{$\mathrm{DE}$} \\
\hline & \multirow{2}{*}{$\frac{\text { Model 1 }}{0.295(0.099)^{*}}$} & \multicolumn{2}{|c|}{ Model 2} & \multirow{2}{*}{$\begin{array}{c}\text { Model } 3 \\
-0.015(0.106)\end{array}$} \\
\hline & & 0.301 & $(0.097)^{*}$ & \\
\hline Intercept & $2.614(0.102)^{* * *}$ & 2.625 & $(0.100)^{* * *}$ & $2.691(0.110)^{* * *}$ \\
\hline Age & $0.439(0.106)^{* * *}$ & 0.524 & $(0.117)^{* * *}$ & $0.608(0.124)^{* * *}$ \\
\hline $\mathrm{Age}^{2}$ & $0.459(0.256)^{\wedge}$ & 0.464 & $(0.256)^{\wedge}$ & $0.424(0.270)$ \\
\hline Birth year & $0.041(0.011)^{* *}$ & 0.042 & $(0.012)^{* *}$ & $0.049(0.012)^{* * *}$ \\
\hline Birth year $^{2}$ & $0.004(0.003)^{\wedge}$ & 0.005 & $(0.003)^{\wedge}$ & $0.005(0.003)^{\wedge}$ \\
\hline Gender & $0.085(0.029)^{* *}$ & 0.073 & $(0.029)^{*}$ & $0.141(0.032)^{* * *}$ \\
\hline Non-native & $-0.186(0.42)^{* * *}$ & -0.159 & $(0.044)^{* *}$ & $-0.040(0.047)$ \\
\hline Low educated & $-0.347(0.037)^{* * *}$ & -0.333 & $(0.039)^{* * *}$ & $-0.111(0.041)^{* *}$ \\
\hline High educated & $0.280(0.036)^{* * *}$ & 0.235 & $(0.038)^{* * *}$ & $0.094(0.040)^{*}$ \\
\hline Age $*$ birth year & $0.092(0.051)^{\wedge}$ & 0.096 & $(0.051)^{\wedge}$ & $0.087(0.054)^{\wedge}$ \\
\hline Age $*$ gender & & -0.118 & $(0.067)^{\wedge}$ & $0.019(0.071)$ \\
\hline Age $*$ non-native & & 0.054 & $(0.098)$ & $0.090(0.104)$ \\
\hline Age $*$ low educated & & 0.142 & $(0.086)^{\wedge}$ & $0.066(0.091)$ \\
\hline Age $*$ high educated & & -0.262 & $(0.082)^{* *}$ & $-0.298(0.086)^{* *}$ \\
\hline Birth year $*$ gender & & -0.00 & $(0.007)$ & $0.002(0.007)$ \\
\hline Birth year $*$ non-native & & -0.0005 & $(0.009)$ & $0.000(0.010)$ \\
\hline Birth year $*$ low educated & & 0.015 & $(0.009)^{\wedge}$ & $0.010(0.009)$ \\
\hline Birth year $*$ high educated & & -0.015 & $(0.008)^{\wedge}$ & $-0.019(0.008)^{*}$ \\
\hline Income assessment & & & & $-1.083(0.047)^{* * *}$ \\
\hline Divorced & & & & $-0.750(0.049)^{* * *}$ \\
\hline Widowed & & & & $-1.021(0.062)^{* * *}$ \\
\hline Never married & & & & $-0.789(0.051)^{* * *}$ \\
\hline Have child & & & & $0.060(0.040)$ \\
\hline Excellent health status & & & & $0.615(0.054)^{* * *}$ \\
\hline Fair health status & & & & $-0.598(0.035)^{* * *}$ \\
\hline Poor health status & & & & $-1.271(0.051)^{* * *}$ \\
\hline Part-time work & & & & $0.015(0.049)$ \\
\hline Unemployed & & & & $-0.548(0.075)^{* * *}$ \\
\hline Retired & & & & $-0.050(0.053)$ \\
\hline Social interaction & & & & $0.304(0.017)^{* * *}$ \\
\hline Random-period & $0.017(0.012)^{\wedge}$ & 0.017 & $(0.012)^{\wedge}$ & $0.019(0.013)^{\wedge}$ \\
\hline Random-cohort & $0.018(0.013)^{\wedge}$ & 0.016 & $(0.011)^{\wedge}$ & $0.004(0.004)$ \\
\hline-2 Res log pseudo-likelihood & $155,710.671$ & 155,8 & 816.065 & $164,609.403$ \\
\hline
\end{tabular}

Continued 
Table 2:

Continued

\begin{tabular}{|c|c|c|c|}
\hline & \multicolumn{3}{|c|}{$\mathrm{ES}$} \\
\hline & Model 1 & Model 2 & Model 3 \\
\hline Intercept & $0.415(0.109)^{* *}$ & $0.432(0.110)^{* *}$ & $-0.155(0.134)$ \\
\hline Intercept & $3.188(0.116)^{* * *}$ & $3.211(0.117)^{* * *}$ & $2.840(0.139)^{* * *}$ \\
\hline Age & $0.063(0.116)$ & $0.179(0.146)$ & $0.289(0.147)^{*}$ \\
\hline $\mathrm{Age}^{2}$ & $-0.074(0.269)$ & $-0.088(0.268)$ & $-0.133(0.263)$ \\
\hline Birth year & $0.019(0.012)^{\wedge}$ & $0.021(0.015)$ & $0.035(0.014)^{*}$ \\
\hline Birth year $^{2}$ & $-0.001(0.003)$ & $-0.001(0.003)$ & $-0.001(0.003)$ \\
\hline Gender & $-0.149(0.036)^{* * *}$ & $-0.158(0.037)^{* * *}$ & $-0.029(0.041)$ \\
\hline Non-native & $-0.260(0.065)^{* * *}$ & $-0.180(0.079)^{*}$ & $-0.038(0.083)$ \\
\hline Low educated & $-0.140(0.049)^{* *}$ & $-0.155(0.051)^{* *}$ & $0.044(0.054)$ \\
\hline High educated & $0.049(0.055)$ & $-0.018(0.066)$ & $-0.137(0.069)^{*}$ \\
\hline Age $*$ birth year & $-0.019(0.054)$ & $-0.025(0.054)$ & $-0.033(0.052)$ \\
\hline Age $*$ gender & & $-0.193(0.080)^{*}$ & $-0.072(0.084)$ \\
\hline Age $*$ non-native & & $0.377(0.148)^{*}$ & $0.382(0.155)^{*}$ \\
\hline Age $*$ low educated & & $-0.105(0.106)$ & $-0.049(0.111)$ \\
\hline Age $*$ high educated & & $0.082(0.122)$ & $0.090(0.127)$ \\
\hline Birth year $*$ gender & & $-0.007(0.008)$ & $-0.005(0.008)$ \\
\hline Birth year $*$ non-native & & $0.025(0.014)^{\wedge}$ & $0.024(0.015)^{\wedge}$ \\
\hline Birth year $*$ low educated & & $-0.006(0.010)$ & $-0.002(0.011)$ \\
\hline Birth year $*$ high educated & & $0.015(0.012)$ & $0.013(0.012)$ \\
\hline Income assessment & & & $-0.583(0.047)^{* * *}$ \\
\hline Divorced & & & $-0.821(0.079)^{* * *}$ \\
\hline Widowed & & & $-0.781(0.080)^{* * *}$ \\
\hline Never married & & & $-0.576(0.070)^{* * *}$ \\
\hline Have child & & & $0.222(0.222)^{* *}$ \\
\hline Excellent health status & & & $0.759(0.064)^{* * *}$ \\
\hline Fair health status & & & $-0.344(0.045)^{* * *}$ \\
\hline Poor health status & & & $-0.884(0.065)^{* * *}$ \\
\hline Part-time work & & & $0.044(0.065)$ \\
\hline Unemployed & & & $-0.420(0.073)^{* * *}$ \\
\hline Retired & & & $0.059(0.072)$ \\
\hline Social interaction & & & $0.240(0.022)^{* * *}$ \\
\hline Random-period & $0.023(0.016)^{\wedge}$ & $0.023(0.016)^{\wedge}$ & $0.022(0.015)^{\wedge}$ \\
\hline Random-cohort & $0.009(0.009)$ & $0.009(0.009)$ & $0.003(0.004)$ \\
\hline-2 Res log pseudo-likelihood & $98,292.313$ & $98,450.663$ & $100,356.5$ \\
\hline
\end{tabular}

Continued 
Table 2:

Continued

\begin{tabular}{|c|c|c|c|}
\hline & \multicolumn{3}{|c|}{ GB } \\
\hline & Model 1 & Model 2 & Model 3 \\
\hline Intercept & $0.497(0.127)^{* *}$ & $0.506(0.122)^{* *}$ & $-0.159(0.118)$ \\
\hline Intercept & $2.661(0.130)^{* * *}$ & $2.675(0.125)^{* * *}$ & $2.238(0.121)^{* * *}$ \\
\hline Age & $0.152(0.067)^{*}$ & $0.070(0.098)$ & $0.043(0.112)$ \\
\hline $\mathrm{Age}^{2}$ & $0.095(0.133)$ & $0.096(0.138)$ & $-0.110(0.166)$ \\
\hline Birth year & $0.006(0.007)$ & $-0.002(0.010)$ & $-0.003(0.011)$ \\
\hline Birth year ${ }^{2}$ & $0.0001(0.001)$ & $0.000(0.001)$ & $-0.002(0.002)$ \\
\hline Gender & $0.144(0.032)^{* * *}$ & $0.135(0.035)^{* * *}$ & $0.171(0.037)^{* * *}$ \\
\hline Non-native & $-0.162(0.044)^{* *}$ & $-0.192(0.050)^{* *}$ & $-0.072(0.053)$ \\
\hline Low educated & $-0.123(0.039)^{* *}$ & $-0.118(0.042)^{* *}$ & $0.106(0.44)^{*}$ \\
\hline High educated & $0.214(0.043)^{* * *}$ & $0.198(0.048)^{* * *}$ & $0.049(0.051)$ \\
\hline Age $*$ birth year & $0.010(0.026)$ & $0.009(0.027)$ & $-0.028(0.033)$ \\
\hline Age $*$ gender & & $0.108(0.075)$ & $0.093(0.078)$ \\
\hline Age $*$ non-native & & $0.082(0.104)$ & $0.161(0.108)$ \\
\hline Age $*$ low educated & & $0.004(0.089)$ & $0.096(0.093)$ \\
\hline Age $*$ high educated & & $0.053(0.100)$ & $-0.027(0.104)$ \\
\hline Birth year $*$ gender & & $0.019(0.007)^{* *}$ & $0.015(0.007)^{*}$ \\
\hline Birth year $*$ non-native & & $0.013(0.010)$ & $0.016(0.010)$ \\
\hline Birth year $*$ low educated & & $-0.011(0.009)$ & $-0.004(0.009)$ \\
\hline Birth year $*$ high educated & & $0.006(0.010)$ & $-0.002(0.010)$ \\
\hline Income assessment & & & $-0.830(0.046)^{* * *}$ \\
\hline Divorced & & & $-0.684(0.055)^{* * *}$ \\
\hline Widowed & & & $-0.904(0.082)^{* * *}$ \\
\hline Never married & & & $-0.444(0.059)^{* * *}$ \\
\hline Have child & & & $0.040(0.051)$ \\
\hline Excellent health status & & & $0.599(0.044)^{* * *}$ \\
\hline Fair health status & & & $-0.504(0.044)^{* * *}$ \\
\hline Poor health status & & & $-0.841(0.064)^{* * *}$ \\
\hline Part-time work & & & $0.045(0.051)$ \\
\hline Unemployed & & & $-0.299(0.084)^{* *}$ \\
\hline Retired & & & $0.393(0.069)^{* * *}$ \\
\hline Social interaction & & & $0.290(0.018)^{* * *}$ \\
\hline Random-period & $0.003(0.003)$ & $0.003(0.003)$ & $0.005(0.005)$ \\
\hline Random-cohort & $0.068(0.055)$ & $0.058(0.046)^{\wedge}$ & $0.020(0.017)$ \\
\hline-2 Res log pseudo-likelihood & $126,688.981$ & $126,884.011$ & $129,745.022$ \\
\hline
\end{tabular}

Continued 
Table 2:

Continued

\begin{tabular}{|c|c|c|c|}
\hline & \multicolumn{3}{|c|}{ HU } \\
\hline & Model 1 & Model 2 & Model 3 \\
\hline Intercept & $-0.953(0.133)^{* *}$ & $-0.943(0.132)^{* * *}$ & $-1.226(0.143)^{* * *}$ \\
\hline Intercept & $1.260(0.133)^{* * *}$ & $1.273(0.132)^{* * *}$ & $1.349(0.144)^{* * *}$ \\
\hline Age & $-0.073(0.180)$ & $0.048(0.193)$ & $0.043(0.163)$ \\
\hline $\mathrm{Age}^{2}$ & $0.640(0.018)$ & $0.644(0.394)^{\wedge}$ & $0.446(0.319)$ \\
\hline Birth year & $0.005(0.018)$ & $0.018(0.019)$ & $0.005(0.016)$ \\
\hline Birth year $^{2}$ & $0.007(0.0045)^{\wedge}$ & $0.007(0.004)^{\wedge}$ & $0.005(0.003)$ \\
\hline Gender & $0.151(0.036)^{* * *}$ & $0.132(0.036)^{* *}$ & $0.375(0.039)^{* * *}$ \\
\hline Non-native & $0.080(0.099)$ & $0.123(0.104)$ & $0.228(0.109)^{*}$ \\
\hline Low educated & $-0.472(0.040)^{* * *}$ & $-0.470(0.41)^{* * *}$ & $-0.074(0.044)^{\wedge}$ \\
\hline High educated & $0.440(0.053)^{* * *}$ & $0.428(0.055)^{* * *}$ & $0.155(0.057)^{* *}$ \\
\hline Age $*$ birth year & $0.133(0.079)^{\wedge}$ & $0.133(0.079)^{\wedge}$ & $0.088(0.064)$ \\
\hline Age $*$ gender & & $-0.129(0.080)^{\wedge}$ & $-0.100(0.083)$ \\
\hline Age $*$ non-native & & $0.477(0.222)^{*}$ & $0.537(0.231)^{*}$ \\
\hline Age $*$ low educated & & $-0.088(0.88)$ & $-0.056(0.092)$ \\
\hline Age $*$ high educated & & $-0.135(0.121)$ & $-0.099(0.126)$ \\
\hline Birth year $*$ gender & & $-0.005(0.008)$ & $-0.007(0.008)$ \\
\hline Birth year $*$ non-native & & $0.041(0.021)^{\wedge}$ & $0.045(0.022)^{*}$ \\
\hline Birth year $*$ low educated & & $-0.018(0.009)^{*}$ & $-0.011(0.009)$ \\
\hline Birth year $*$ high educated & & $-0.013(0.012)$ & $-0.003(0.012)$ \\
\hline Income assessment & & & $-0.947(0.042)^{* * *}$ \\
\hline Divorced & & & $-0.585(0.057)$ \\
\hline Widowed & & & $-0.555(0.065)^{* * *}$ \\
\hline Never married & & & $-0.425(0.079)^{* * *}$ \\
\hline Have child & & & $0.188(0.068)^{* *}$ \\
\hline Excellent health status & & & $0.861(0.079)^{* * *}$ \\
\hline Fair health status & & & $-0.507(0.046)^{* * *}$ \\
\hline Poor health status & & & $-1.279(0.062)^{* * *}$ \\
\hline Part-time work & & & $0.017(0.077)$ \\
\hline Unemployed & & & $-0.172(0.091)^{\wedge}$ \\
\hline Retired & & & $0.160(0.060)^{* *}$ \\
\hline Social interaction & & & $0.278(0.021)^{* * *}$ \\
\hline Random-period & $0.057(0.038)^{\wedge}$ & $0.056(0.037)^{\wedge}$ & $0.035(0.027)^{\wedge}$ \\
\hline Random-cohort & $0.002(0.004)$ & $0.002(0.004)$ & $0.002(0.004)$ \\
\hline-2 Res log pseudo-likelihood & $80,577.945$ & $80,689.226$ & $85,067.865$ \\
\hline
\end{tabular}

Continued 
Table 2:

Continued

\begin{tabular}{|c|c|c|c|}
\hline & & IE & \\
\hline & Model 1 & Model 2 & Model 3 \\
\hline Intercept & $0.155(0.133)$ & $0.201(0.130)$ & $-0.635(0.144)^{* *}$ \\
\hline Intercept & $2.449(0.136)^{* * *}$ & $2.499(0.133)^{* * *}$ & $1.894(0.146)^{* * *}$ \\
\hline Age & $-0.215(0.192)$ & $-0.271(0.200)$ & $-0.331(0.178)^{\wedge}$ \\
\hline $\mathrm{Age}^{2}$ & $1.189(0.411)^{* *}$ & $1.166(0.405)^{* *}$ & $0.761(0.362)^{*}$ \\
\hline Birth year & $-0.038(0.019)^{*}$ & $-0.054(0.02)^{* *}$ & $-0.061(0.018)^{* *}$ \\
\hline Birth year $^{2}$ & $0.011(0.004)^{* *}$ & $0.011(0.004)^{* *}$ & $0.007(0.004)^{*}$ \\
\hline Gender & $0.076(0.033)^{*}$ & $0.053(0.034)$ & $0.078(0.037)^{*}$ \\
\hline Non-native & $0.021(0.050)$ & $-0.027(0.059)$ & $0.155(0.062)^{*}$ \\
\hline Low educated & $-0.298(0.041)^{* * *}$ & $-0.326(0.042)^{* * *}$ & $-0.088(0.044)^{*}$ \\
\hline High educated & $0.227(0.041)^{* * *}$ & $0.116(0.047)^{*}$ & $-0.024(0.049)$ \\
\hline Age $*$ birth year & $0.229(0.082)^{* *}$ & $0.223(0.081)^{* *}$ & $0.141(0.072)^{*}$ \\
\hline Age $*$ gender & & $-0.024(0.08)$ & $-0.006(0.083)$ \\
\hline Age $*$ non-native & & $0.012(0.127)$ & $0.013(0.132)$ \\
\hline Age $*$ low educated & & $-0.014(0.097)$ & $0.037(0.101)$ \\
\hline Age $*$ high educated & & $0.270(0.0102)^{* *}$ & $0.268(0.106)^{* *}$ \\
\hline Birth year $*$ gender & & $0.006(0.008)$ & $0.003(0.008)$ \\
\hline Birth year $*$ non-native & & $0.009(0.012)$ & $0.008(0.012)$ \\
\hline Birth year $*$ low educated & & $0.005(0.010)$ & $0.010(0.010)$ \\
\hline Birth year $*$ high educated & & $0.038(0.010)^{* *}$ & $0.034(0.010)^{* *}$ \\
\hline Income assessment & & & $-0.656(0.043)^{* * *}$ \\
\hline Divorced & & & $-0.531(0.082)^{* * *}$ \\
\hline Widowed & & & $-0.625(0.090)^{* * *}$ \\
\hline Never married & & & $-0.265(0.062)^{* * *}$ \\
\hline Have child & & & $0.176(0.057)^{* *}$ \\
\hline Excellent health status & & & $0.768(0.040)^{* * *}$ \\
\hline Fair health status & & & $-0.466(0.050)^{* * *}$ \\
\hline Poor health status & & & $-0.923(0.102)^{* * *}$ \\
\hline Part-time work & & & $-0.052(0.051)$ \\
\hline Unemployed & & & $-0.658(0.066)^{* * *}$ \\
\hline Retired & & & $-0.070(0.069)$ \\
\hline Social interaction & & & $0.273(0.021)^{* * *}$ \\
\hline Random-period & $0.067(0.042)^{\wedge}$ & $0.063(0.040)^{\wedge}$ & $0.044(0.029)^{\wedge}$ \\
\hline Random-cohort & $0.004(0.005)$ & $0.003(0.004)$ & $0.005(0.006)$ \\
\hline-2 Res log pseudo-likelihood & $123,900.008$ & $123,894.129$ & $126,807.087$ \\
\hline
\end{tabular}

Continued 
Table 2:

Continued

\begin{tabular}{|c|c|c|c|}
\hline & \multicolumn{3}{|c|}{ NL } \\
\hline & Model 1 & Model 2 & Model 3 \\
\hline Intercept & $0.646(0.569)$ & $0.645(0.571)$ & $-0.321(0.537)$ \\
\hline Intercept & $3.679(0.572)^{* *}$ & $3.681(0.574)^{* * *}$ & $2.980(0.541)^{* *}$ \\
\hline Age & $-2.920(0.446)^{* * *}$ & $-3.037(0.452)^{* * *}$ & $-2.705(0.468)^{* * * *}$ \\
\hline $\mathrm{Age}^{2}$ & $2.124(0.603)^{* *}$ & $2.099(0.604)^{* *}$ & $2.386(0.637)^{* *}$ \\
\hline Birth year & $-0.293(0.045)^{* * *}$ & $-0.306(0.045)^{* * *}$ & $-0.271(0.047)^{* * *}$ \\
\hline Birth year ${ }^{2}$ & $0.022(0.006)^{* *}$ & $0.021(0.006)^{* *}$ & $0.024(0.006)^{* *}$ \\
\hline Gender & $0.092(0.039)^{*}$ & $0.072(0.040)^{\wedge}$ & $0.179(0.044)^{* * *}$ \\
\hline Non-native & $-0.426(0.061)^{* * *}$ & $-0.376(0.068)^{* * *}$ & $-0.018(0.074)$ \\
\hline Low educated & $-0.303(0.046)^{* * *}$ & $-0.290(0.047)^{* * *}$ & $-0.113(0.050)^{*}$ \\
\hline High educated & $0.149(0.05)^{* *}$ & $0.144(0.055)^{* *}$ & $0.034(0.058)$ \\
\hline Age $*$ birth year & $0.428(0.120)^{* *}$ & $0.421(0.121)^{* * *}$ & $0.479(0.127)^{*}$ \\
\hline Age $*$ gender & & $0.109(0.089)$ & $0.138(0.094)$ \\
\hline Age $*$ non-native & & $0.067(0.139)$ & $0.137(0.150)$ \\
\hline Age $*$ low educated & & $-0.013(0.104)$ & $0.101(0.110)$ \\
\hline Age $*$ high educated & & $0.197(0.115)^{\wedge}$ & $0.242(0.120)^{*}$ \\
\hline Birth year $*$ gender & & $0.020(0.009)^{*}$ & $0.015(0.009)^{\wedge}$ \\
\hline Birth year $*$ non-native & & $-0.001(0.013)$ & $0.002(0.015)$ \\
\hline Birth year $*$ low educated & & $-0.007(0.010)$ & $0.002(0.011)$ \\
\hline Birth year $*$ high educated & & $0.019(0.011)^{\wedge}$ & $0.022(0.012)^{\wedge}$ \\
\hline Income assessment & & & $-0.881(0.063)^{* * *}$ \\
\hline Divorced & & & $-0.909(0.077)^{* * *}$ \\
\hline Widowed & & & $-1.175(0.104)^{* * *}$ \\
\hline Never married & & & $-0.488(0.075)^{* * *}$ \\
\hline Have child & & & $0.171(0.060)^{* *}$ \\
\hline Excellent health status & & & $0.774(0.073)^{* * *}$ \\
\hline Fair health status & & & $-0.607(0.048)^{* * *}$ \\
\hline Poor health status & & & $-1.110(0.090)^{* * *}$ \\
\hline Part-time & & & $0.008(0.055)$ \\
\hline Unemployed & & & $-0.551(0.114)^{* * *}$ \\
\hline Retired & & & $0.172(0.086)^{*}$ \\
\hline Social interaction & & & $0.346(0.022)^{* * *}$ \\
\hline Random-period & $2.42(1.497)^{*}$ & $2.442(1.505)^{*}$ & $2.084(1.330)^{\wedge}$ \\
\hline Random-cohort & $0.006(0.006)$ & $0.005(0.005)$ & $0.003(0.005)$ \\
\hline-2 Res log pseudo-likelihood & $126,774.107$ & $126,774.406$ & $127,196.860$ \\
\hline
\end{tabular}

Continued 
Table 2:

Continued

\begin{tabular}{|c|c|c|c|}
\hline & \multicolumn{3}{|c|}{ NO } \\
\hline & Model 1 & Model 2 & Model 3 \\
\hline Intercept & $0.931(0.078)^{* * *}$ & $0.928(0.078)^{* * *}$ & $-0.454(0.132)^{*}$ \\
\hline Intercept & $3.558(0.096)^{* * *}$ & $3.556(0.095)^{* * *}$ & $2.410(0.141)^{* * *}$ \\
\hline Age & $0.313(0.082)^{* *}$ & $0.323(0.114)^{* *}$ & $0.313(0.110)^{* *}$ \\
\hline $\mathrm{Age}^{2}$ & $0.181(0.201)$ & $0.176(0.200)$ & $0.212(0.174)$ \\
\hline Birth year & $0.029(0.008)^{* *}$ & $0.025(0.011)^{*}$ & $0.033(0.011)^{* *}$ \\
\hline Birth year $^{2}$ & $0.001(0.002)$ & $0.001(0.002)$ & $0.002(0.002)$ \\
\hline Gender & $0.081(0.043)^{\wedge}$ & $0.082(0.044)^{\wedge}$ & $0.149(0.047)^{* *}$ \\
\hline Non-native & $-0.179(0.072)^{*}$ & $-0.170(0.081)^{*}$ & $0.080(0.087)$ \\
\hline Low educated & $-0.096(0.056)^{\wedge}$ & $-0.082(0.059)$ & $0.178(0.062)^{* *}$ \\
\hline High educated & $-0.070(0.053)$ & $-0.078(0.055)$ & $-0.221(0.059)^{* *}$ \\
\hline Age $*$ birth year & $0.033(0.040)$ & $0.030(0.040)$ & $0.040(0.034)$ \\
\hline Age $*$ gender & & $-0.059(0.097)$ & $-0.032(0.102)$ \\
\hline Age $*$ non-native & & $0.352(0.166)^{*}$ & $0.325(0.174)^{\wedge}$ \\
\hline Age $*$ low educated & & $-0.044(0.127)$ & $-0.053(0.133)$ \\
\hline Age $*$ high educated & & $0.003(0.117)$ & $-0.016(0.123)$ \\
\hline Birth year $*$ gender & & $0.000(0.009)$ & $-0.002(0.010)$ \\
\hline Birth year $*$ non-native & & $0.030(0.06)^{*}$ & $0.022(0.016)$ \\
\hline Birth year $*$ low educated & & $0.000(0.012)$ & $-0.002(0.013)$ \\
\hline Birth year $*$ high educated & & $0.002(0.011)$ & $-0.001(0.012)$ \\
\hline Income assessment & & & $-0.889(0.082)^{* * *}$ \\
\hline Divorced & & & $-0.724(0.067)^{* * *}$ \\
\hline Widowed & & & $-0.793(0.105)^{* * *}$ \\
\hline Never married & & & $-0.573(0.067)^{* * *}$ \\
\hline Have child & & & $0.400(0.068)^{* * *}$ \\
\hline Excellent health status & & & $0.636(0.059)^{* * *}$ \\
\hline Fair health status & & & $-0.460(0.060)^{* * *}$ \\
\hline Poor health status & & & $-0.931(0.088)^{* * *}$ \\
\hline Part-time & & & $0.097(0.078)$ \\
\hline Unemployed & & & $-0.754(0.142)^{* * *}$ \\
\hline Retired & & & $0.290(0.092)^{* *}$ \\
\hline Social interaction & & & $0.411(0.030)^{* * *}$ \\
\hline Random-period & $0.007(0.007)$ & $0.007(0.007)$ & $0.004(0.005)$ \\
\hline Random-cohort & $0.005(0.006)$ & $0.004(0.006)$ & $0.001(0.003)$ \\
\hline-2 Res log pseudo-likelihood & $93,022.950$ & $93,086.183$ & $95,724.636$ \\
\hline
\end{tabular}

Continued 
Table 2:

Continued

\begin{tabular}{|c|c|c|c|}
\hline & \multicolumn{3}{|c|}{ PT } \\
\hline & Model 1 & Model 2 & Model 3 \\
\hline Intercept & $-0.086(0.319)$ & $-0.046(0.312)$ & $-0.685(0.264)^{*}$ \\
\hline Intercept & $2.730(0.320)^{* * *}$ & $2.783(0.313)^{* * *}$ & $2.337(0.265)^{* * *}$ \\
\hline Age & $0.364(0.349)$ & $0.453(0.365)$ & $0.462(0.322)$ \\
\hline $\mathrm{Age}^{2}$ & $-1.279(0.592)^{*}$ & $-1.181(0.591)^{*}$ & $-0.419(0.545)$ \\
\hline Birth year & $0.054(0.035)$ & $0.047(0.036)$ & $0.046(0.032)$ \\
\hline Birth year $^{2}$ & $-0.014(0.006)^{*}$ & $-0.013(0.006)^{*}$ & $-0.005(0.005)$ \\
\hline Gender & $-0.214(0.033)^{* * *}$ & $-0.246(0.034)^{* * *}$ & $0.007(0.035)$ \\
\hline Non-native & $0.153(0.072)^{*}$ & $0.210(0.096)^{*}$ & $0.373(0.099)^{* *}$ \\
\hline Low educated & $-0.238(0.051)^{* * *}$ & $-0.307(0.067)^{* * *}$ & $-0.005(0.069)$ \\
\hline High educated & $0.282(0.074)^{* *}$ & $0.299(0.104)^{* *}$ & $0.199(0.106)^{\wedge}$ \\
\hline Age $*$ birth year & $-0.271(0.118)^{*}$ & $-0.255(0.118)^{*}$ & $-0.099(0.109)$ \\
\hline Age $*$ gender & & $0.184(0.075)^{*}$ & $0.265(0.077)^{* *}$ \\
\hline Age $*$ non-native & & $0.498(0.168)^{* *}$ & $0.612(0.173)^{* *}$ \\
\hline Age $*$ low educated & & $-0.255(0.118)^{*}$ & $-0.194(0.121)$ \\
\hline Age $*$ high educated & & $-0.026(0.178)$ & $-0.031(0.181)$ \\
\hline Birth year $*$ gender & & $0.034(0.007)^{* * *}$ & $0.035(0.007)^{* * *}$ \\
\hline Birth year $*$ non-native & & $0.045(0.017)^{* *}$ & $0.051(0.017)^{* *}$ \\
\hline Birth year $*$ low educated & & $-0.017(0.011)$ & $-0.018(0.012)$ \\
\hline Birth year $*$ high educated & & $-0.005(0.017)$ & $-0.008(0.017)$ \\
\hline Income assessment & & & $-0.574(0.037)^{* * *}$ \\
\hline Divorced & & & $-0.619(0.076)^{* * *}$ \\
\hline Widowed & & & $-0.687(0.072)^{* * *}$ \\
\hline Never married & & & $-0.324(0.070)^{* * *}$ \\
\hline Have child & & & $0.042(0.059)$ \\
\hline Excellent health status & & & $0.430(0.077)^{* * *}$ \\
\hline Fair health status & & & $-0.331(0.040)^{* * *}$ \\
\hline Poor health status & & & $-1.027(0.057)^{* * *}$ \\
\hline Part-time & & & $-0.109(0.058)^{\wedge}$ \\
\hline Unemployed & & & $-0.146(0.065)^{*}$ \\
\hline Retired & & & $0.078(0.055)$ \\
\hline Social interaction & & & $0.222(0.020)^{* * *}$ \\
\hline Random-period & $0.541(0.383)^{\wedge}$ & $0.525(0.374)^{\wedge}$ & $0.293(0.240)$ \\
\hline Random-cohort & $0.055(0.045)$ & $0.033(0.029)$ & $0.016(0.015)$ \\
\hline -2 Res log pseudo-likelihood & $103,419.412$ & $103,808.587$ & $105,352.371$ \\
\hline
\end{tabular}

Continued 
Table 2:

Continued

\begin{tabular}{|c|c|c|c|}
\hline \multirow[b]{3}{*}{ Intercept } & \multicolumn{3}{|c|}{ SE } \\
\hline & \multirow{2}{*}{$\frac{\text { Model 1 }}{0.758(0.061)^{* * *}}$} & \multirow{2}{*}{$\frac{\text { Model } 2}{0.760(0.062)^{* * *}}$} & Model 3 \\
\hline & & & $-0.131 \quad(0.118)$ \\
\hline Intercept & $3.357(0.078)^{* * *}$ & $3.363(0.079)^{* * *}$ & $2.798(0.127)^{* * *}$ \\
\hline Age & $-0.012(0.050)$ & $0.106(0.093)$ & $0.062(0.104)$ \\
\hline $\mathrm{Age}^{2}$ & $0.273(0.126)^{*}$ & $0.271(0.128)^{*}$ & $0.325(0.155)^{*}$ \\
\hline Birth year & $-0.004(0.005)$ & $-0.001(0.009)$ & $-0.001 \quad(0.010)$ \\
\hline Birth year $^{2}$ & $0.003(0.001)^{*}$ & $0.002(0.001)^{\wedge}$ & $0.003(0.002)^{\wedge}$ \\
\hline Gender & $0.057(0.041)$ & $0.057(0.041)$ & $0.201(0.045)^{* * *}$ \\
\hline Non-native & $-0.260(0.057)^{* * *}$ & $-0.257(0.059)^{* * *}$ & $-0.033 \quad(0.064)$ \\
\hline Low educated & $-0.070(0.050)$ & $-0.065(0.052)$ & $0.158(0.056)^{* *}$ \\
\hline High educated & $0.063(0.054)$ & $0.034(0.059)$ & $-0.141 \quad(0.063)^{*}$ \\
\hline Age $*$ birth year & $0.053(0.025)^{*}$ & $0.048(0.025)^{\wedge}$ & $0.053(0.031)^{\wedge}$ \\
\hline Age $*$ gender & & $-0.188(0.091)^{*}$ & $-0.227 \quad(0.097)^{*}$ \\
\hline Age $*$ non-native & & $0.212(0.128)^{\wedge}$ & $0.231(0.137)^{\wedge}$ \\
\hline Age $*$ low educated & & $-0.209(0.110)^{\wedge}$ & $-0.167 \quad(0.118)$ \\
\hline Age $*$ high educated & & $0.096(0.121)$ & $0.117 \quad(0.128)$ \\
\hline Birth year $*$ gender & & $-0.011(0.009)$ & $-0.020 \quad(0.009)^{*}$ \\
\hline Birth year $*$ non-native & & $0.018(0.012)$ & $0.015 \quad(0.013)$ \\
\hline Birth year $*$ low educated & & $-0.011(0.011)$ & $-0.006 \quad(0.012)$ \\
\hline Birth year $*$ high educated & & $0.013(0.012)$ & $0.014 \quad(0.013)$ \\
\hline Income assessment & & & $-0.949(0.075)^{* * *}$ \\
\hline Divorced & & & $-0.744(0.064)^{* * *}$ \\
\hline Widowed & & & $-0.992(0.096)^{* * *}$ \\
\hline Never married & & & $-0.690(0.060)^{* * *}$ \\
\hline Have child & & & $0.376(0.063)^{* * * *}$ \\
\hline Excellent health status & & & $0.725(0.058)^{* * *}$ \\
\hline Fair health status & & & $-0.712(0.055)^{* * *}$ \\
\hline Poor health status & & & $-1.573(0.093)^{* * *}$ \\
\hline Part-time & & & $0.235 \quad(0.098)^{*}$ \\
\hline Unemployed & & & $-0.452(0.118)^{* *}$ \\
\hline Retired & & & $0.244(0.087)^{* *}$ \\
\hline Social interaction & & & $0.277(0.025)^{* * *}$ \\
\hline Random-period & $0.001(0.003)$ & $0.001(0.003)$ & $0.002(0.004)$ \\
\hline Random-cohort & $0.003(0.004)$ & $0.003(0.004)$ & $0.0001(0.003)$ \\
\hline-2 Res log pseudo-likelihood & $97,714.566$ & $97,895.511$ & $102,930.973$ \\
\hline
\end{tabular}

Continued 
Table 2:

Continued

\begin{tabular}{|c|c|c|c|}
\hline & & SI & \\
\hline & Model 1 & Model 2 & Model 3 \\
\hline Intercept & $-0.037(0.101)$ & $-0.041(0.101)$ & $-0.815(0.101)^{* *}$ \\
\hline Intercept & $2.487(0.107)^{* * *}$ & $2.485(0.107)^{* * *}$ & $1.988(0.107)^{* * *}$ \\
\hline Age & $0.025(0.115)$ & $-0.021(0.147)$ & $0.060(0.147)$ \\
\hline $\mathrm{Age}^{2}$ & $-0.107(0.286)$ & $-0.109(0.287)$ & $-0.129(0.287)$ \\
\hline Birth year & $0.020(0.012)^{\wedge}$ & $0.013(0.015)$ & $0.016(0.015)$ \\
\hline Birth year $^{2}$ & $-0.001(0.003)$ & $-0.001(0.003)$ & $-0.001(0.003)$ \\
\hline Gender & $0.081(0.045)^{\wedge}$ & $0.089(0.046)^{*}$ & $0.267(0.046)^{* * *}$ \\
\hline Non-native & $0.149(0.067)^{*}$ & $0.144(0.066)^{*}$ & $0.180(0.066)^{* *}$ \\
\hline Low educated & $-0.550(0.051)^{* * *}$ & $-0.545(0.051)^{* * *}$ & $-0.216(0.051)^{* * *}$ \\
\hline High educated & $0.404(0.073)^{* * *}$ & $0.402(0.078)^{* * *}$ & $0.223(0.078)^{* *}$ \\
\hline Age $*$ birth year & $-0.027(0.057)$ & $-0.026(0.057)$ & $-0.035(0.057)$ \\
\hline Age $*$ gender & & $0.018(0.102)$ & $0.059(0.102)$ \\
\hline Age $*$ non-native & & $-0.039(0.148)$ & $0.0001(0.148)$ \\
\hline Age $*$ low educated & & $0.098(0.113)$ & $0.058(0.113)$ \\
\hline Age $*$ high educated & & $-0.057(0.164)$ & $-0.088(0.164)$ \\
\hline Birth year $*$ gender & & $0.004(0.010)$ & $0.000(0.010)$ \\
\hline Birth year $*$ non-native & & $-0.011(0.014)$ & $0.000(0.014)$ \\
\hline Birth year $*$ low educated & & $0.013(0.011)$ & $0.010(0.011)$ \\
\hline Birth year $*$ high educated & & $-0.004(0.016)$ & $-0.005(0.016)$ \\
\hline Income assessment & & & $-0.714(0.150)^{* * *}$ \\
\hline Divorced & & & $-0.636(0.153)^{* * *}$ \\
\hline Widowed & & & $-0.696(0.141)^{* * *}$ \\
\hline Never married & & & $-0.452(0.257)^{* * *}$ \\
\hline Have child & & & $0.189(0.014)^{*}$ \\
\hline Excellent health status & & & $0.760(0.003)^{* * *}$ \\
\hline Fair health status & & & $-0.637(0.049)^{* * * *}$ \\
\hline Poor health status & & & $-1.142(0.069)^{* * *}$ \\
\hline Part-time & & & $0.097(0.054)$ \\
\hline Unemployed & & & $-0.237(0.082)^{*}$ \\
\hline Retired & & & $0.182(0.106)^{*}$ \\
\hline Social interaction & & & $0.316(0.154)^{* * *}$ \\
\hline Random-period & $0.018(0.014)^{\wedge}$ & $0.018(0.014)^{\wedge}$ & $0.013(0.011)$ \\
\hline Random-cohort & $0.006(0.007)$ & $0.006(0.007)$ & $0.004(0.237)$ \\
\hline -2 Res log pseudo-likelihood & $60,276.65$ & $60,313.82$ & $62,773.84$ \\
\hline
\end{tabular}

Note: ${ }^{\wedge} p<.1 ;{ }^{*} p<.05 ;{ }^{* *} p<.01 ;{ }^{* * *} p<.0001$. 


\section{Figure 3:}

Graphical plot of the estimated cohort and period effects on high happiness [overall 95\% confidence interval (low/high)] in ten countries based on model 1
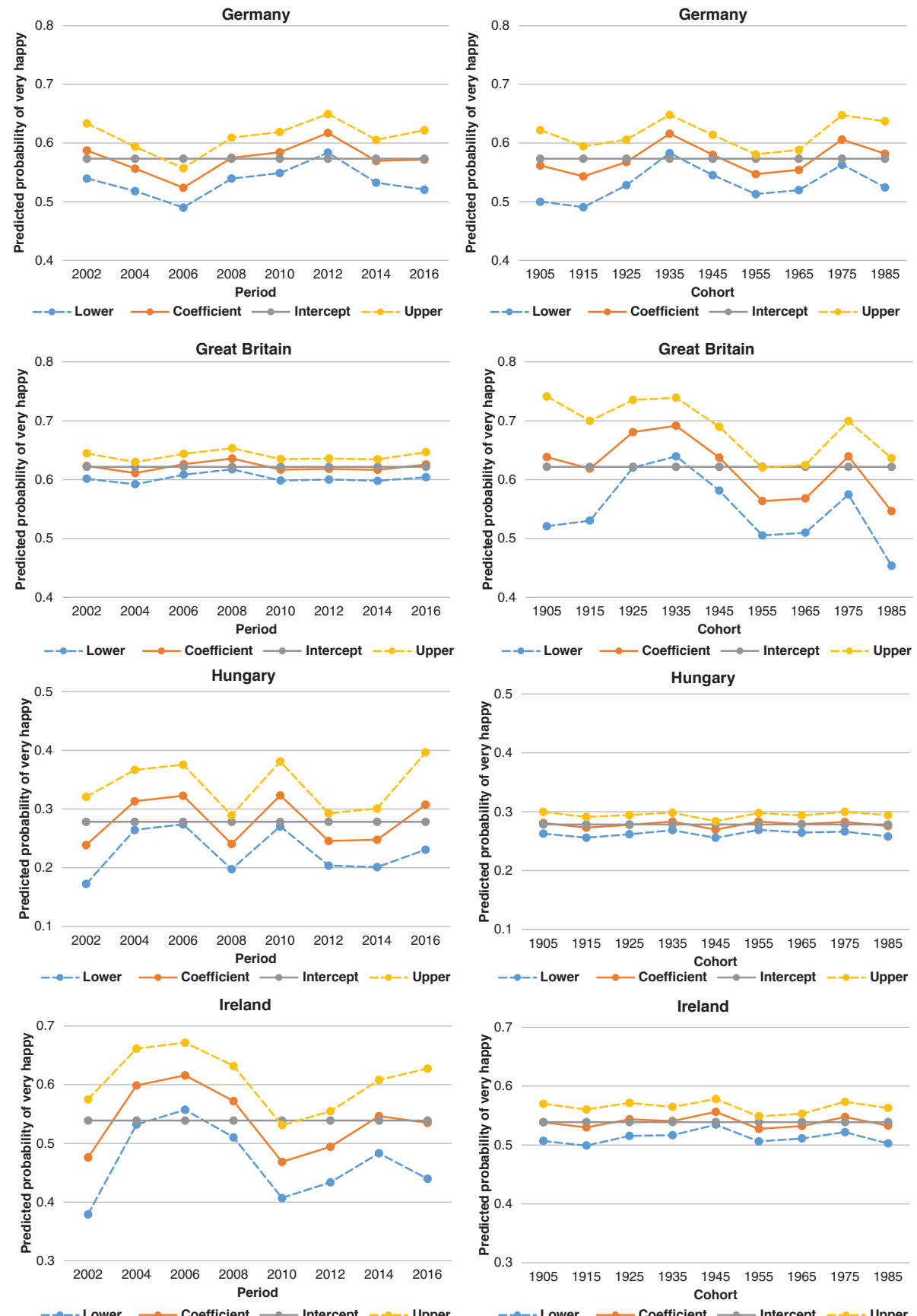


\section{Figure 3:}

\section{Continued}
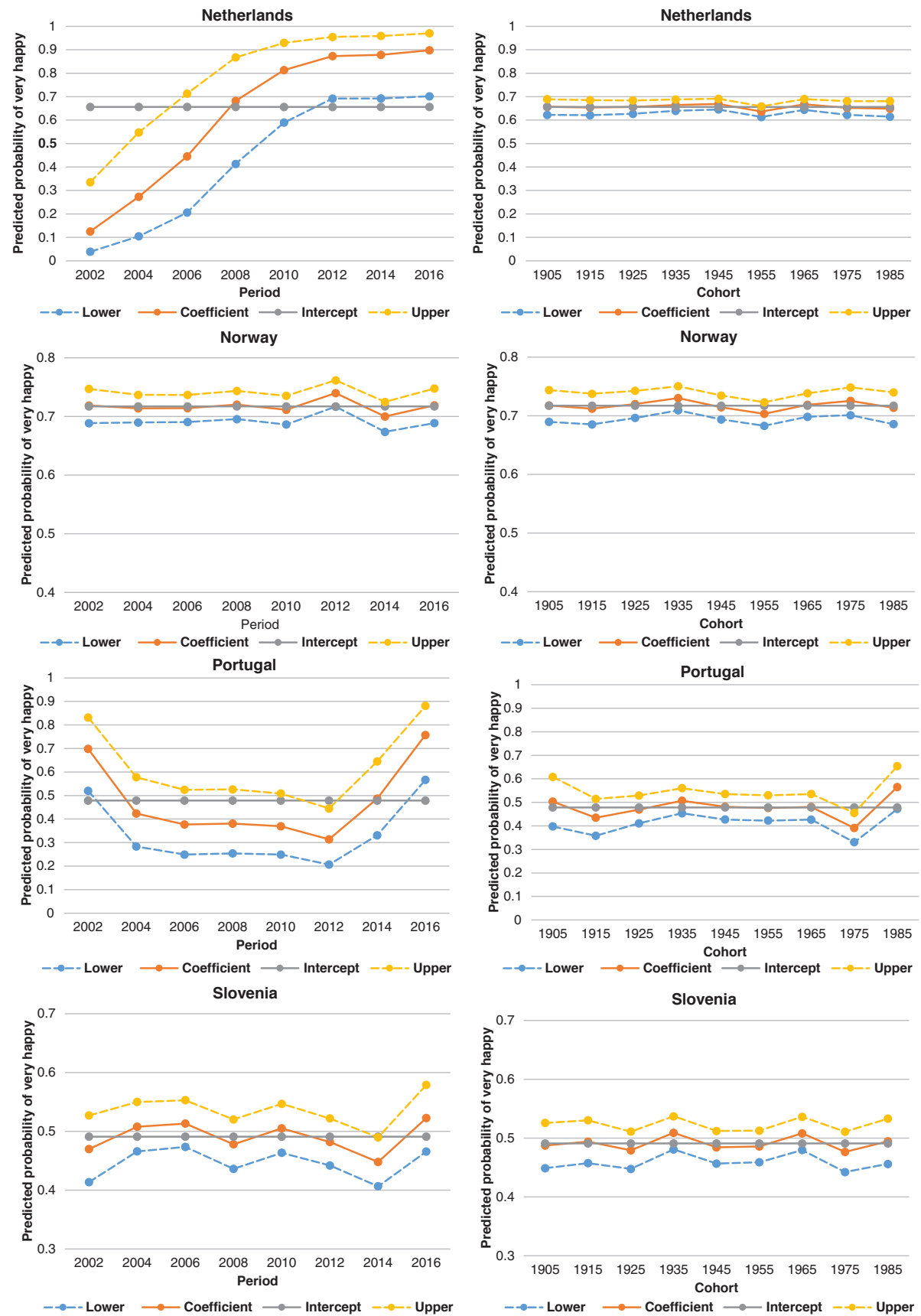
Figure 3:

\section{Continued}
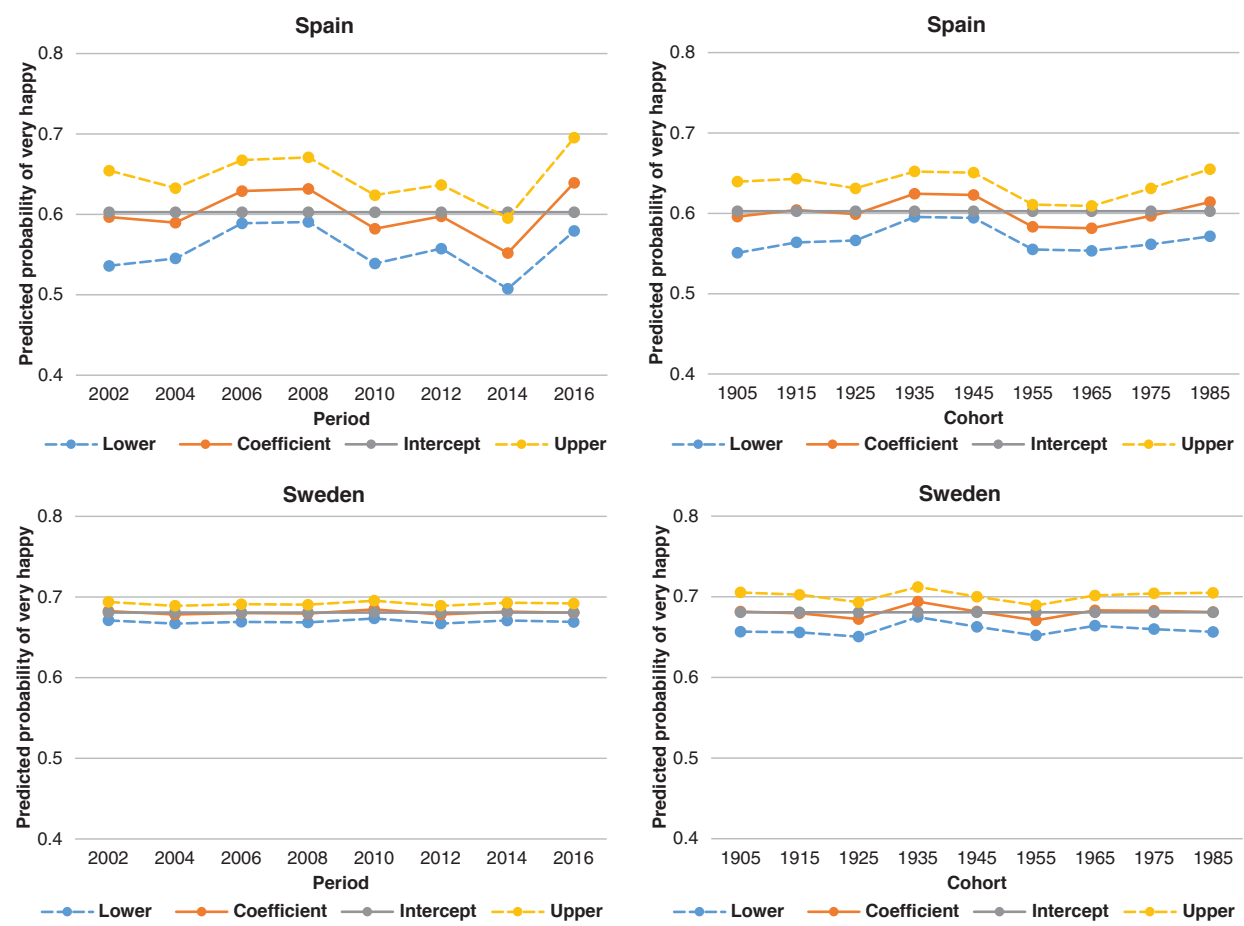

Note: The corresponding figures in each country graphically plot the estimated cohorts and time period effects within the 95 percent confidence bounds.

than early baby boomers (i.e., those born in 1945-1954). These relatively high levels of happiness found for pre-baby boomers are in line with our first assumption. Furthermore, even though our models assume no period linear trends, we find lower happiness in the study period (2002-2016), with a decline around 2008 or thereafter in some countries (ES, HU, IE, PT), followed by a recovery (NL, PT).

\subsection{Core socio-economic determinants of happiness}

We now turn our attention to the core socio-economic determinants shown in model 1 in Table 2. On average, as expected (H2a), women, native people and people with higher levels of educational attainment are more likely to be very happy than men, non-native people and people with lower levels of educational attainment. However, the evidence for Southern European countries is mixed. For some countries, negative effects are found for being female (ES, PT), but positive 
effects are found for being non-native (PT). The age effects are observed to be larger for more recent cohorts in several countries (DE, HU, IE, NL, SE), but in Portugal, the opposite pattern is found (i.e., age effects are larger for less recent cohorts).

As expected, the effects of socio-economic characteristics change over the life course (Inglehart 2002; Ferraro and Shippee 2009), as presented in Model 2. Here, we find a more mixed picture than we anticipated (H2b), with growing (dis)advantages for certain socio-economic characteristics in some countries, and decreasing gaps for other types of socio-economic characteristics in other countries. First, we observe that the differences in levels of happiness due to gender evolve over the life course. In some countries (DE, HU), women do not remain happy throughout their life course. We also find that women in two Southern European countries have distinct experiences. In Portugal, women are generally not happier than men, but variations are observed at older ages. In Spain, women are generally unhappy, and remain so over their life course. When we look at place of origin, we see that in one Southern European country (PT), non-natives have higher levels of happiness throughout the life course. In other countries, the low levels happiness associated with being non-native disappear (DE, GB, NL), or turn into high levels happiness (ES, NO, SE), showing a strong trend towards convergence. Such crossover trends are also observed for education. The association of lower levels of educational attainment with lower levels of happiness disappears over the life course in many countries. However, in one Western European country (DE), people with lower levels of educational attainment are less happy when they are middle-aged, but are happier at older ages. In one Southern European country (PT), people with lower levels of educational attainment remain consistently less happy, while lower educated people in one Northern European country (SE) become less happy at older ages. Highly educated people remain happier throughout the life course in noncontinental and Western European countries (IE, NL). However, there are crossovers in age effects in Germany, where the highly educated are not happy at older ages. The effects of core socio-economic characteristics change by cohort, but to a much lesser extent than in the case of age.

\subsection{Additional socio-economic, demographic and behavioural determinants of happiness, and time variations}

In full model 3, additional determinants - income assessment, employment status, partnership status, child status, health status and social interaction behaviour - are introduced. In line with the second hypothesis, all of these determinants produce significant and consistent effects on happiness. As expected, we observe that happiness is highly dependent on socio-economic and demographic characteristics, and our findings are largely in line with previous empirical research (Angeles 2010; Niedzwiedz et al. 2015; Steptoe et al. 2015; Glass et al. 2016; Read et al. 2016; Jenkinson et al. 2020). A negative assessment of income has a consistent negative effect on happiness. Those individuals who are divorced, widowed or never married 
are less likely to be happy than those who are married. Unemployed people are also less likely to be happy, while retired people are more likely to be happy in selected countries across regions (GB, HU, NO, SE, SI). People in poor or even fair health are less likely to have high levels of happiness than those reporting excellent health. People who are more socially active are more likely to be happy than those who are less active. Being a parent has a positive effect in all countries except Germany, Great Britain and Portugal, although the size of the effect differs across countries.

By including additional covariates, we can show changes in the aforementioned time and core covariates (i.e., gender, native/non-native, levels of educational attainment) and interaction effects found in previous model 2. This implies that core socio-economic covariates are mediated by additional characteristics that are controlled for, in particular income assessment, marital status, employment status and health status. Model 3 shows that for the time factors, the same age patterns are generally observed, albeit with decreased net effects for period and cohort. For the age effect, the same trend is generally found. Even though fixed effects of age and polynomial age do not always show significant effects for all countries, a U-shaped relationship between age and happiness emerges for one Southern European country (ES), while a non-U-shaped pattern is observed for a non-continental Western European country (GB). The negative age trends found for another Southern European country (PT) point to a slight recovery at older ages, although the effects are not significant.

The associations of the core socio-economic covariates vary. Figure A.1 (Appendix) illustrates the probabilities of being very happy from model 3 in Table 2, which compares the age trajectories by the core socio-economic characteristics (i.e., gender, place of origin and levels of education). Female advantages are now observed in all countries except one Southern European country (ES). The negative association with being non-native disappears in most countries, while being non-native remains an advantage in Southern and Eastern European countries only (PT, SI), and becomes an advantage in Eastern and non-continental Western European countries (HU, IE). The disadvantage of being less educated remains for a few countries, extends to more countries (DE, HU, IE, NL, SI), and disappears for Southern European countries (ES, PT), but turns into an advantage for Westerncontinental and Northern European countries (GB, NO, SE). The advantage of being highly educated remains for countries across regions (DE, HU, PT, SI), but disappears for other non-continental Western and Western European countries (GB, IE, NL), and appears as a disadvantage in still other countries across regions (ES, NO, SE). As we can see, these changes in associations do not reflect the geographical classification of countries.

The interaction effects between age and core socio-economic characteristics in model 3 exhibit substantial country-specific patterns. When controlling for additional covariates, the female disadvantages at older ages disappear for several countries (DE, ES, HU). We find, for example, that Portuguese women are happier, but Swedish women not. Interestingly, non-natives are happier than natives in a few countries across regions (ES, HU, NO, PT, SE), whereas low levels of educational 
attainment and happiness levels are no longer significant. This educational gap also decreases among the highly educated as changes of coefficients are observed for Western European countries. For instance, highly educated people in Germany are unhappy, whereas highly educated people in the Netherlands and Ireland remain happier than less educated people. Gaps in levels of happiness by core socioeconomic characteristics vary by cohort, but to a much lesser extent than by age, as was the case for model 2 . The observation that women, native people and highly educated people are not happier than their counterparts over the life course (age), and to some extent in more recent generations (cohort), is partially explained by marital status, partnership and child status, health status and income assessment.

\section{Discussion and conclusion}

This paper aimed to show the trajectories of subjective well-being (SWB) through measures of happiness, as influenced by time and socio-economic, demographic and behavioural determinants. We approached this research objective by seeking to answer two research questions: 1 . What are the effects of different dimensions of time (age, period, cohort) on people's levels of happiness? 2. And, do we observe differences in people's happiness levels depending on their socio-economic, demographic and behavioural characteristics, controlled for time effects?

Our results show a U-shaped relationship between age and happiness for some countries, but a rather flat age pattern for others. Some countries exhibit positive age effects at higher ages $(80+)$, while others show negative effects. Lower happiness levels are generally found for baby boomers, but variations within the baby boom generation (1945-1964) are also observed (i.e., lower levels of happiness for late boomers (1955-1964) than for earlier boomers (1945-1954). No linear trend over time in period residuals is assumed, while period contextual effects are found for some countries (all except Northern European countries) in relation to the economic crisis (2008) and thereafter. Happiness levels are affected by individual characteristics controlled by time: on average, women, higher educated people and native people have higher levels of happiness than men, lower educated people and non-native people, respectively. Moreover, a positive income assessment, having a partner, being a parent, being employed, being in good health and being socially active all have positive effects on levels of happiness. When controlling for these additional covariates (i.e., marital status, partnership and child status, employment and health status and own income assessment), the association between core socio-economic characteristics and happiness weakens. For instance, on average, the advantage of being a women remains, but mixed results are observed for native/non-native status and levels of educational attainment. We find that in some countries, women, native people and highly educated people are not happier than their counterparts over the life course (age), and to some extent in more recent generations (cohort). These variations can be partially explained by marital and child status, health status and own income assessment. 
Some findings are in line with our empirical research, while others are not. Some evidence of a U-shaped relationship between age and happiness is found for some countries, but not all countries follow this pattern. Other studies have identified negative happiness by age trends for Eastern European countries (Steptoe et al. 2015), but our study found such results for only one Southern European country (PT). Recent empirical research (Blanchflower 2021) reconfirming a U-shaped ageSWB pattern globally appears to be in contrast with our findings on different age trends of happiness (i.e., non-U-shaped). The happiness variations among older seniors in our findings provide new insights into happiness-age trends, while cohort effects, and particularly low happiness levels among baby boomers, are reconfirmed (Barrett and Toothman 2014), albeit with cross-national differences. Our observations that levels of happiness are higher among women, native people and highly educated people than among their counterparts are supported by other research. However, after controlling for additional covariates (i.e., marital status, partnership and child status, employment and health status, and own income assessment), the relationship between core socio-economic characteristics and happiness levels weakens. Moreover, the degrees of these levels varied across countries. Our finding that time and heterogeneous life course happiness trajectories have countryspecific trends, rather than geographical characteristics, supports previous findings (Helliwell et al. 2019). For instance, inequalities in happiness due to levels of education are noted even in Western European countries, where reasonable social welfare provisions are in place. The existing happiness gaps among the highly educated in these countries deserve further attention. Moreover, the decreasing happiness gaps by educational level found in all other countries may simply be due to varying age affects over the life course resulting in less heterogeneity and non-differential happiness trends at older ages.

The key strengths of our analysis include the use of semi-longitudinal and crossnationally comparable data and the application of (extended) hierarchical ageperiod-cohort models to examine comparatively the consistency of results on time trends of happiness. Another strength was our use of a wide range of measures, including core socio-economic characteristics (i.e., gender, non-native, educational levels) and additional socio-economic, demographic and behavioural characteristics in the model for each country. The latter allowed us to study comparatively the social differentials of happiness levels and their varying age effects.

There are a few points to consider. The measure of self-reported happiness used in this paper covered only one side of SWB. In order to capture the full multi-dimensional breadth of the concept, future studies should also take into account eudemonic (i.e., human flourishing or prosperity) measures and objective health measures of physical capabilities (i.e., mental health) (Abdallah et al. 2011; OECD 2013). Survival bias may have partially affected our results, in particular the non-U-shaped relation between age and SWB for some countries, leading to variations in age effects among older seniors. In some countries, the survival status of the elderly is likely to also be associated with their higher happiness levels and their attention to emotional goals and experiences, as socioemotional 
selectivity theory explains (Carstensen et al. 2003). The proportion of the population who are institutionalised is also higher among the elderly, and this proportion differs substantially across countries because of diverse living arrangements crossnationally, which creates additional biases (Schanze and Levinson 2019). In other words, the socio-economic and demographic differentials among the older age group are considered to be smaller in Northern and Western European countries than in Southern and Eastern European countries. In addition, we do not deny that countryspecific cultural factors may affect how people respond to survey questions on happiness. We have not fully explored measurement equivalence across countries (Davidov et al. 2014), and our constructed three-point happiness scales may have discounted small differences in levels of happiness, although this choice was made because of concentrated response choices in the original scales. Moreover, as our findings are based on assumptions by constraining period trends while examining age and cohort effects in the hierarchical age-period-cohort (HAPC) model, the period effects of, for instance, the economic crisis may be undermined for some countries. However, the experiences of people in their earlier years of life are considered to be larger than the general time period effects influencing all ages. Finally, we used a semi-longitudinal survey design to perform an extension of the HAPC analysis, even though true individual changes over time can only be studied through surveys with a longitudinal design with repeated measurements on the same individual.

Our study has important implications for future research. Inequalities in happiness that are associated with people's experiences and accumulation of socio-economic and demographic characteristics during adulthood can widen later in life, and this trend may be stronger among younger generations. Future research should focus on the areas that are negatively influencing the socio-economic and demographic determinants of happiness among various sub-groups of the population in order to improve the chances that these happiness gaps will decrease later in life. This kind of research will be particularly relevant as the late baby boomers - a more socioeconomically heterogeneous group than the early boomers - join the young senior group in the coming decade. Insights we obtain about age-happiness trends can provide additional useful lessons for the younger generations, such as Generations $\mathrm{X}, \mathrm{Y}$ (Millennials) and $\mathrm{Z}$, who are undergoing new and different challenges in adulthood (e.g., COVID-19) that were not experienced by previous generations.

\section{Acknowledgements}

An early version of this paper was presented at the UNECE Second International Seminar on Active Ageing Index, held in Bilbao, Spain, on 27-28 September 2018. The research was funded by the University of Leuven Geconcerteerde Onderzoeksactie (GOA) project New Approaches to the Social Dynamics of Long-term Fertility Change (Grant GOA/14/001, https://soc.kuleuven.be/ceso/fapos/nasdltfc/ index). Finally, we are thankful for the many substantial and insightful comments 
and suggestions provided by two anonymous reviewers, the editor and the editorial team that improved this article.

\section{References}

Aassve, A., L. Mencarini and M. Sironi 2015. Institutional change, happiness and fertility. European Sociological Review 31(6): 749-765. https://doi.org/10.1093/esr/jcv073

Abdallah, S., S. Mahony, N. Marks, J. Michaelson, C. Seaford, L. Stoll and S. Thompson 2011. Measuring our progress: The power of well-being. Centre for Well-being. The New Economics Foundation. Download from https://neweconomics.org/uploads/files/ Measuring_our_Progress.pdf, accessed on 20 June 2016.

Angeles, L. 2010. Children and life satisfaction. Journal of Happiness Studies 11: 523-538. https://doi.org/10.1007/s10902-009-9168-z

Barrett, A. E. and E. L. Toothman 2014. Babyboomers' subjective life course and its physical health effects: How distinctive is the "forever young" cohort? International Journal of Ageing and Human Development 79(2): 109-129. https://doi.org/10.2190/AG.79.2.b

Bell, A. and K. Jones 2013. The impossibility of separating age, period and cohort effects. Social Science $\mathcal{E}$ Medicine 93: 163-165. https://doi.org/10.1016/j.socscimed.2013.04.029

Bell, A. 2014. Life course and cohort trajectories of mental health in the UK 1991-2008 A multilevel age-period-cohort analysis. Social Science $\mathcal{E}$ Medicine 120: 21-30. https: //doi.org/10.1016/j.socscimed.2014.09.008

Bell, A. and K. Jones 2015. Age, period and cohort processes in longitudinal and life course analysis: A multilevel perspective. In A life course perspective on health trajectories and transitions. Life course research and social policies, eds C. Burton-Jeangros, S. Cullati, A. Sacker and D. Blane, vol. 4. 197-213. Cham: Springer. https://doi.org/10.1007/978-3319-20484-0_10

Blanchflower, D. G. and A. J. Oswald 2008. Is well-being U-shaped over the life cycle? Social Science $\mathcal{E}$ Medicine 66(8): 1733-1749. https://doi.org/10.1016/j.socscimed.2008.01.030

Blanchflower, D. G. 2021. Is happiness U-shaped everywhere? Age and subjective well-being in 145 countries. Journal of Population Economics 34: 575-624. https://doi.org/10.1007/ s00148-020-00797-z.

Brown, S. L. and Wright, M. R. 2017. Marriage, cohabitation and divorce in later life. Innovation in Ageing 1(2): 1-11. https://doi.org/10.1093/geroni/igx015

Carstensen, L. L., H. H. Fung and S. T. Charles 2003. Socioemotional selectivity theory and the regulation of emotion in the second half of life. Motivation and Emotion 27(2): 103-123. https://doi.org/10.1023/A:1024569803230

Clark, A. 2007. Born to be mild? Cohort effects don't (fully) explain why well-being is U-shaped in age. Institute for the Study of Labour. Discussion Paper Series. No. 3170. Download from http://www.parisschoolofeconomics.com/clark-andrew/CohortNov2007. pdf, accessed on 17 September 2017.

Dannefer, D. 2003. Cumulative advantage/disadvantage and the life course: Cross-fertilizing age and social science theory. Journal of Gerontology: Series B 58(6): S327-S337. https://doi.org/10.1093/geronb/58.6.S327 
Davidov, E., B. Meuleman, J. Cieciuch, P. Schmidt and J. Billiet 2014. Measurement equivalence in cross-national research. Annual Review of Sociology 40: 55-75. https: //doi.org/10.1146/annurev-soc-071913-043137

Deeming, C. 2013. Addressing the social determinants of subjective wellbeing: The latest challenge for social policy. Journal of Social Policy 42(3): 541-565. https://doi.org/10. 1017/S0047279413000202

Diener, E. (ed) 2009. The science of well-being: The collected works of Ed Diener. Dordrecht: Springer. https://doi.org/10.1007/978-90-481-2350-6

Easterlin, R. A., C. M. Schaeffer and D. J. Macunovich 1993. Will the baby boomers be less well off than their parents? Income, wealth, and family circumstances over the life cycle in the United States. Population and Development Review 19(3): 497-522. https://doi.org/10.2307/2938464

Easterlin, R. A. 2010. Happiness, growth, and the life cycle, eds H. Hinte and K. F. Zimmermann. Oxford: Oxford University.

European Commission. 2014. Population ageing in Europe: Facts, implications and policies. Directorate General for Research and Innovation. Directorate B Innovation Union and European Research Area Unit B6. Reflective Societies. https://doi.org/10.2777/60452

European Social Survey. 2016. ESS documentation report. Norwegian Social Science Data Services. Download from https://www.europeansocialsurvey.org/data/download.html?r=8

European Social Survey. 2018. ESS1-8 Data Protocol. European Social Survey Data Archive, Norwegian Social Science Data Services. Download from https://www. europeansocialsurvey.org/data/download.html? $\mathrm{r}=8$

Ferraro, K. F. and T. P. Shippee 2009. Aging and cumulative inequality: How does inequality get under the skin? The Gerontologist 49(3): 333-343. https://doi.org/10. 1093\%2Fgeront\%2Fgnp034

Frenk, S. M., Y. C. Yang and K. C. Land 2013. Assessing the significance of cohort and period effects in hierarchical age-period-cohort models: Applications to verbal test scores and voter turnout in U.S. presidential elections. Social Forces 92(1): 221-248. https: //doi.org/10.1093/sf/sot066

Frijters, P. and T. Beatton 2012. The mystery of the U-shaped relationship between happiness and age. Journal of Economics Behaviour and Organization 82(2-3): 525-542. https: //doi.org/10.1016/j.jebo.2012.03.008

Fukuda, K. 2013. A happiness study using age-period-cohort framework. Journal of Happiness Studies 14: 135-153. https://doi.org/10.1007/s10902-011-9320-4

Giele, J. Z. and G. H. Elder, Jr. (eds) 1998. Methods of life course research: Qualitative and quantitative approaches. Thousand Oaks, London, New Delhi: Sage Publications.

Glass, J., R. W. Simon and M. A. Andersson 2016. Parenthood and happiness: Effects of work-family reconciliation policies in 22 OECD countries. American Journal of Sociology 122(3): 886-929. https://doi.org/10.1086/688892

Hadjar, A. and S. Backes 2013. Migration background and subjective well-being a multilevel analysis based on the European Social Survey. Comparative Sociology 12: 645-676. https://doi.org/10.1163/15691330-12341279 
Helliwell, J., R. Layard and Sachs, J. D. eds 2019. World Happiness report 2019. New York, Sustainable Development Solutions Network. Download from https://worldhappiness. report/ed/2019/, accessed on 18 April 2019.

Huppert, F. A. 2009. Psychological well-being: Evidence regarding its causes and consequences. Applied Psychology: Health and Well-being 1(2): 137-164. https://doi.org/ 10.1111/j.1758-0854.2009.01008.x

Inglehart, R. 2002. Gender, ageing, and subjective well-being. International Journal of Comparative Sociology 43(3-5): 391-408. https://doi.org/10.1177/002071520204300309

Jivraj, S., J. Nazroo, B. Vanhoutte and T. Chandola 2014. Aging and subjective well-being in later life. The Journals of Gerontology, series B 69(6): 930-941. https://doi.org/10.1093/ geronb/gbu006

Jenkinson, S., H. Matsuo and K. Matthijs 2020. Multi-dimensional Subjective Wellbeing and Lone Parenthood following Divorce in Flanders (Northern Belgium). In Divorce in Europe: New insights in trends, causes and consequences of relation break-ups, ed D. Mortelmans, 211-236. European Studies of Population 21, Cham: Springer. https: //doi.org/10.1007/978-3-030-25838-2_10

Lesthaeghe, R. 2014. The second demographic transition: A concise overview of its development. PNAS 111(51): 18112-18115. https://doi.org/10.1073/pnas.1420441111

Lin, I.-F. and S. L. Brown 2012. Unmarried boomers confront old age: A national portrait. The Gerontologist 52(2): 153-165. https://doi.org/10.1093/geront/gnr141

Margolis, R. and M. Myrskylä 2011. A global perspective on happiness and fertility. Population Development Review 37(1): 29-56. https://doi.org/10.1111/j.1728-4457.2011. 00389.x

Mencarini, L., D. Vignoli, T. Zeydanli and J. Kim 2018. Life satisfaction favours reproduction. The universal positive effect of life satisfaction on childbearing in contemporary low fertility countries. PLoS ONE 13(12): e0206202. https://doi.org/10.1371/journal.pone. 0206202

Michalos, A. C. 2008. Education, happiness and wellbeing. Social Indicators Research 87: 347-366. https://doi.org/10.1007/s11205-007-9144-0

Myrskylä, M. and R. Margolis 2014. Happiness: Before and after the kids. Demography 51: 1843-1866. https://doi.org/10.1007/s13524-014-0321-X

Niedzwiedz, C. L., J. P. Pell and R. Mitchell 2015. The relationship between financial distress and life course socio-economic inequalities in well-being: Cross-national analysis of European Welfare States. American Journal of Public Health 105(10): 2090-2098. https://doi.org/10.2105/AJPH.2015.302722

OECD 2013. OECD guidelines on measuring subjective well-being. OECD Publishing: Paris. https://doi.org/10.1787/9789264191655-en

OECD 2017. How's life? 2017 Measuring well-being. OECD Publishing: Paris. https://doi. org/10.1787/23089679

OECD 2018. Health at a glance: Europe 2018: State of health in the EU cycle. OECD Publishing: Paris. https://doi.org/10.1787/23056088

OECD 2020. How's life? 2020 Measuring well-being. OECD Publishing: Paris. Download from https://doi.org/10.1787/9870c393-en, accessed on 16 October 2020. 
Oris, M., R. Gabriel, G. Ritschard and M. Kliegel 2017. Long lives and old age poverty: Social stratification and life course institutionalization in Switzerland. Research in Human Development 14(1): 68-87. https://doi.org/10.1080/15427609.2016.1268890.

Ortiz-Ospina, E. and M. Roser 2017. Happiness and Life Satisfaction. Published online at OurWorldInData.org. Download from https://ourworldindata.org/happiness-and-lifesatisfaction, accessed on 28 May 2019.

Pacek, A. and B. Radcliff 2008. Assessing the welfare state: The politics of happiness. Perspectives on Politics 6(2): 267-277. https://doi.org/10.1017/S1537592708080602

Pinquart, M. and S. Sörensen 2000. Influences of socioeconomic status, social network, and competence on subjective well-being in later life: A meta-analysis. Psychology and Aging 15(2): 187-224. https://doi.org/10.1037/0882-7974.15.2.187

Plant, E. A., K. C. Kling and G. L. Smith 2004. The influence of gender and social role on the interpretation of facial expressions. Sex Roles 51: 187-196. https://doi.org/10.1023/B: SERS.0000037762.10349.13

Read, S., E. Grundy and E. Foverskov 2016. Socio-economic position and subjective health and well-being among older people in Europe: A systematic narrative review. Aging $\mathcal{F}$ Mental Health 20(5): 529-542. https://doi.org/10.1080/13607863.2015.1023766

Rowe, J. W. and R. L. Kahn 1997. Successful Ageing. The Gerontologist 37(4): 433-440. https://doi.org/10.1093/geront/37.4.433

Ryder, N. B. 1965. The cohort as a concept in the study of social change. American Sociological Review 30(6): 843-861. https://doi.org/10.2307/2090964

Sand, G. and S. Gruber 2018. Differences in subjective well-being between older migrants and natives in Europe. Journal of Immigrant Minority Health 20: 83-90. https://doi.org/ 10.1007/s10903-016-0537-5

Schanze, J. and M. Levinson 2019. Report on what persons live in institutions and the most relevant institution types they live in, the availability of data to select them and their ability to be reached in practice. Deliverable 2.17 of the SERISS project funded under the European Union's Horizon 2020 research and innovation programme GA No: 654221. Available at: www.seriss.eu/resources/deliverables

Shanahan, M. J., J. T. Mortimer and M. K. Johnson (eds) 2016. Handbook of the life course. vol. II. New York: Springer.

Skevington, S. M. and J. Böhnke 2018. How is subjective well-being related to quality of life? Do we need two concepts and both measures? Social Science $\mathcal{E}$ Medicine 206: 22-30. https://doi.org/10.1016/j.socscimed.2018.04.005

Snijders, T. A. B. and R. J. Bosker 1999. Multilevel analysis: An introduction to basic and advanced multilevel modeling. London: Sage.

Spruk, R. and A. Kešeljević 2016. Institutional origins of subjective well-being: Estimating the effects of economic freedom on national happiness. Journal of Happiness Studies 17: 659-712. https://doi.org/10.1007/s10902-015-9616-x

Stepler, R. 2017. Led by Baby Boomers, divorce rates climb for America's 50+ population. Washington, DC: Fact Tank: Pew Research Center. https://www.pewresearch.org/fact-tank/ 2017/03/09/led-by-baby-boomers-divorce-rates-climb-for-americas-50-population/, accessed on 16 October 2020. 
Steptoe, A., A. Deaton and A. A. Stone 2015. Subjective wellbeing, health and ageing. Lancet 385: 640-648. https://doi.org/10.1016/S0140-6736(13)61489-0

Stiglitz, J. E., A. Sen and J. P. Fitoussi 2009. Report by the Commission on the measurement of economic performance and social progress. Paris: Commission on the Measurement of Economic Performance and Social Progress.

Thompson, S. and N. Marks 2008. Measuring well-being in policy: Issues and applications. London: New Economics Foundation. Download from https://b.3cdn.net/nefoundation/ 575659b4f333001669_ohm6iiogp.pdf, accessed on 29 April 2015.

UNECE/EC 2019. Active ageing index 2018: Analytical report. Report prepared by G. Lamura and A. Principi under contract with United Nations Economic Commission for Europe (Geneva), co-funded by European Commission's Directorate General for Employment, Social Affairs and Inclusion (Brussels). Download from https://www.unece. org/population/aai.html, accessed on 15 July 2019.

Van de Velde, S., P. Bracke and K. Lavecque 2010. Gender differences in depression in 23 European countries. Cross-national variation in the gender gap in depression. Social Science $\mathcal{F}$ Medicine 71(2): 305-313. https://doi.org/10.1016/j.socscimed.2010.03.035

Vanhoutte, B. 2014. The multidimensional structure of subjective well-being in later life. Population Ageing 7: 1-20. https://doi.org/10.1007/s12062-014-9092-9

Welsch, H. and J. Kühling 2016. Macroeconomic performance and institutional change: Evidence from subjective well-being data. Journal of Applied Economics 11(2): 193-218. https://doi.org/10.1016/S1514-0326(16)30008-3

WHO 2015. World report on ageing and health. World Health Organization. https://apps. who.int/iris/handle/10665/186463

Witter, R. A., M. A. Okun, W. A. Stoc and M. J. Haring 1984. Education and subjective well-being: A meta-analysis. Educational Evaluation and Policy Analysis 6(2): 165-173. https://doi.org/10.3102\%2F01623737006002165

Yang, Y. 2008. Social inequalities in happiness in the United States, 1972 to 2004: An age-period-cohort analysis. American Sociological Review 73(2): 204-226. https://doi. org/10.1177/000312240807300202

Yang, Y. and K. Land 2013. Age-period-cohort analysis, new models, methods and empirical applications. Boca Raton: Taylor and Francis group.

Zaidi, A., K. Gasior, E. Zolyomi, A. Schmidt, R. Rodrigues and B. Marin 2017. Measuring active and healthy ageing in Europe. Journal of European Social Policy 27(2): 138-157. https://doi.org/10.1177/0958928716676550 


\section{Appendix}

\section{Figure A.1:}

(a) Predicted age variations in gender effects on happiness based on model 3 in ten countries.
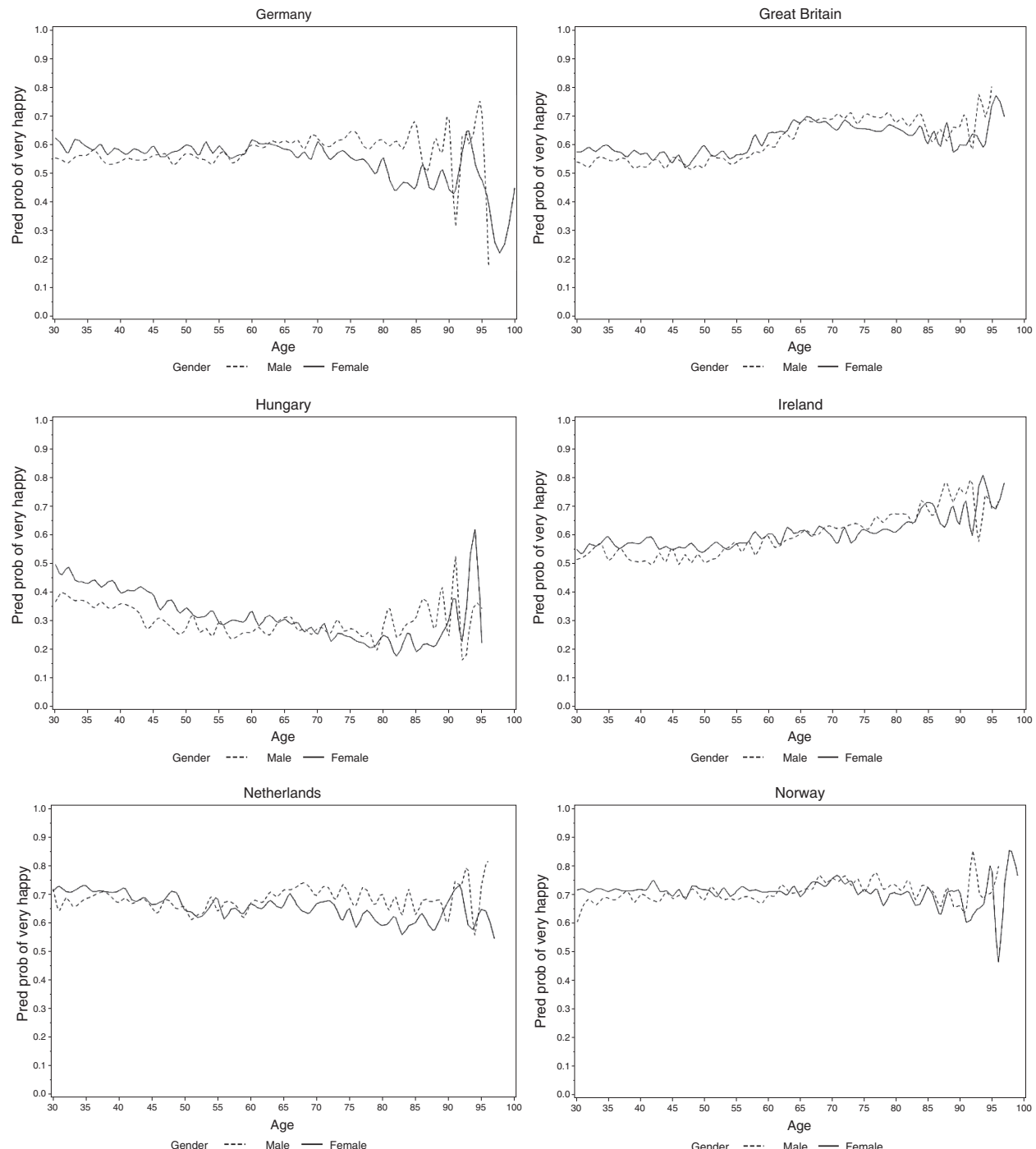
Figure A.1:

(a) Continued
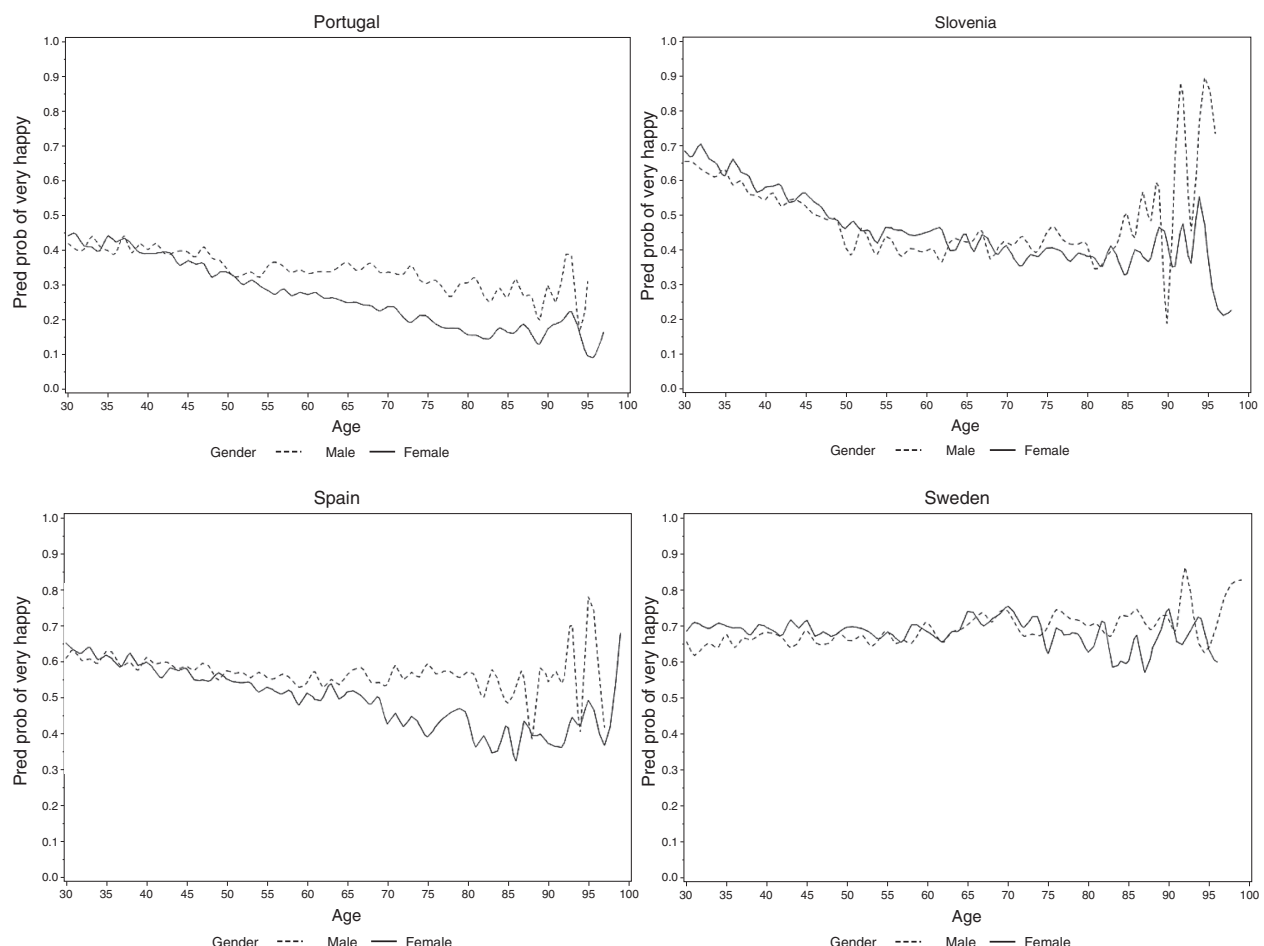


\section{Figure A.1:}

(b) Predicted age variations in place of origin effects on happiness based on model 3 in ten countries.
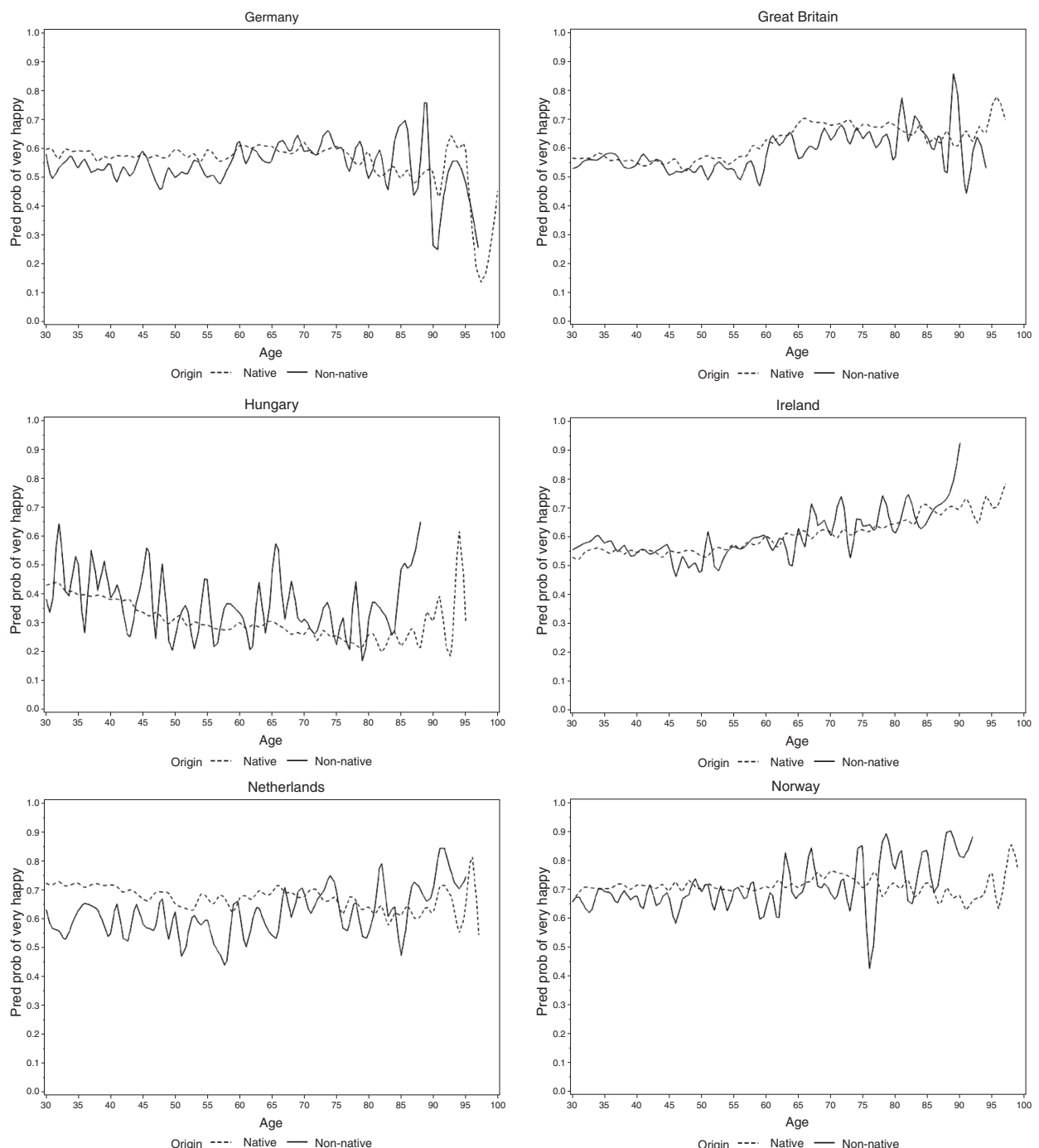


\section{Figure A.1:}

(b) Continued
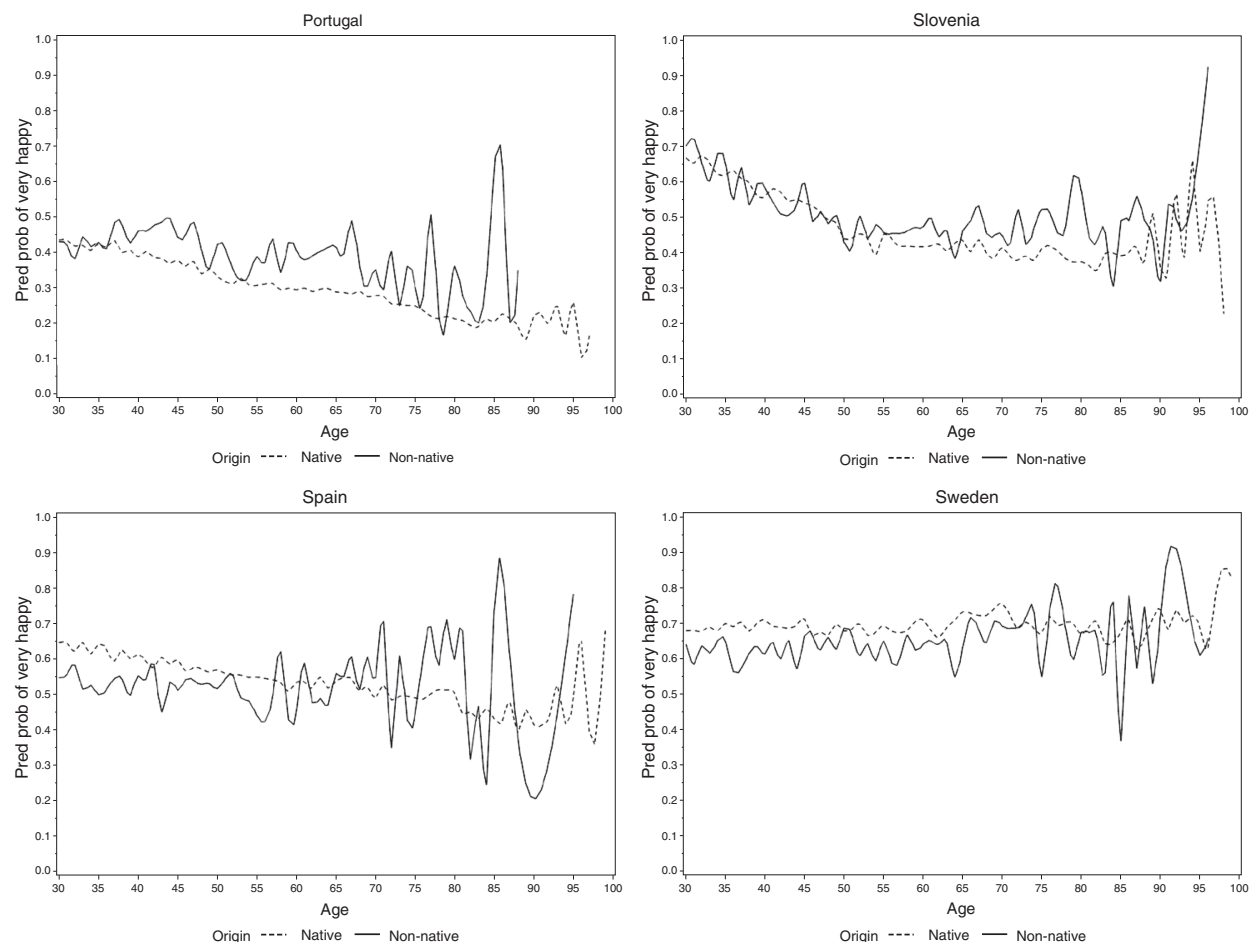


\section{Figure A.1:}

(c) Predicted age variations in low-level education effects on happiness based on model 3 in ten countries.
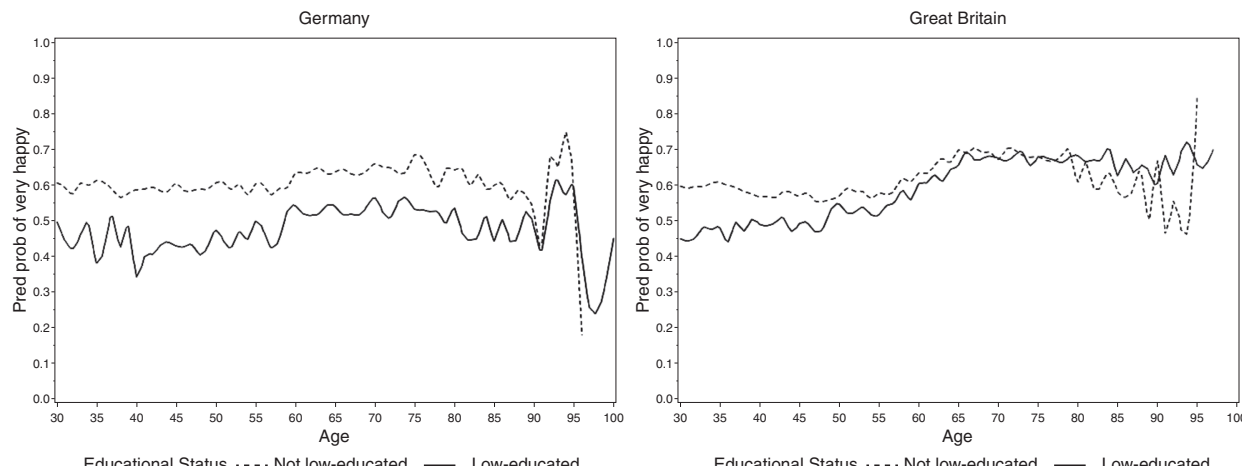

Educational Status .... Not low-educated — Low-educated

Educational Status .... Not low-educated — Low-educated
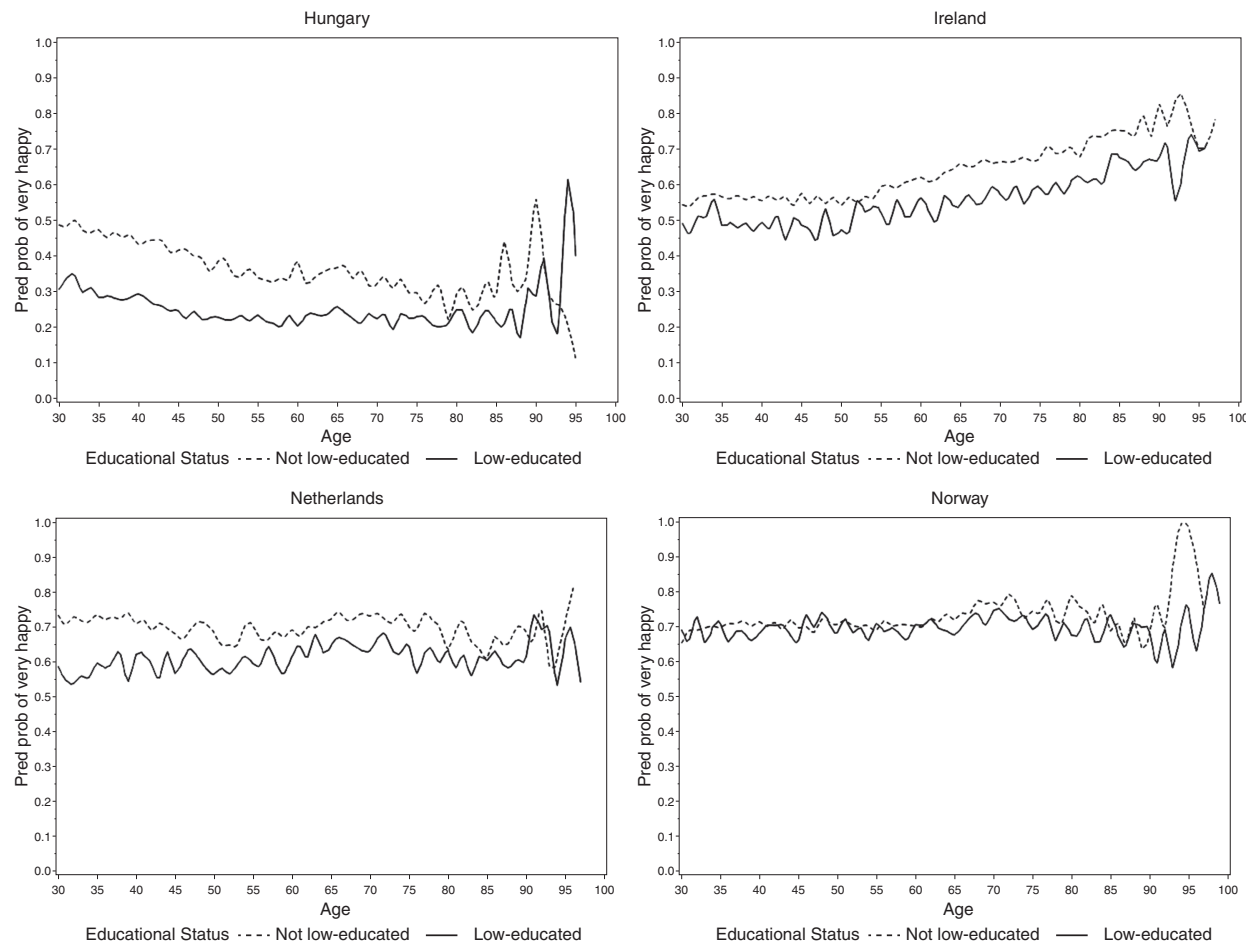


\section{Figure A.1:}

(c) Continued
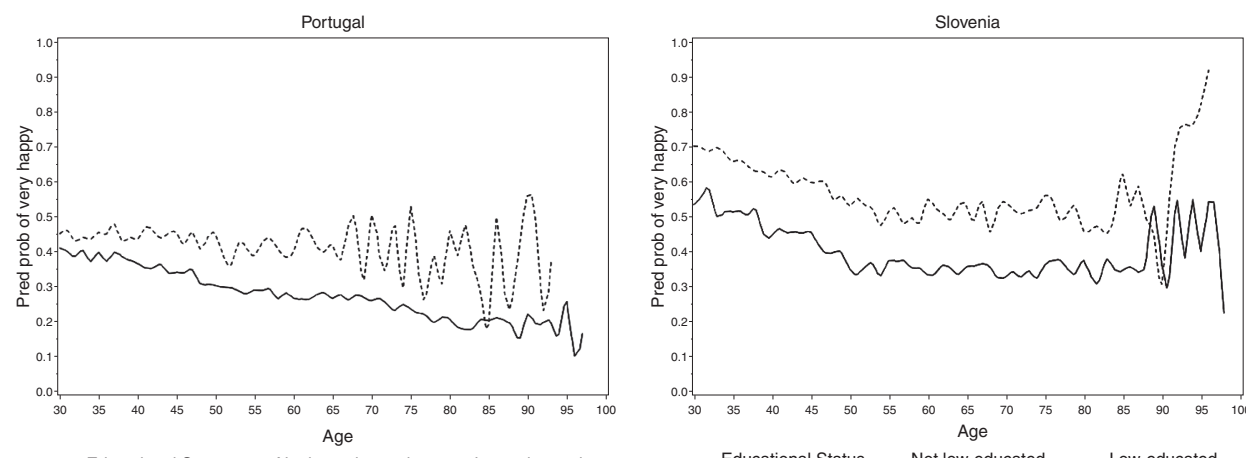

Educational Status .... Not low-educated — Low-educated

Spain
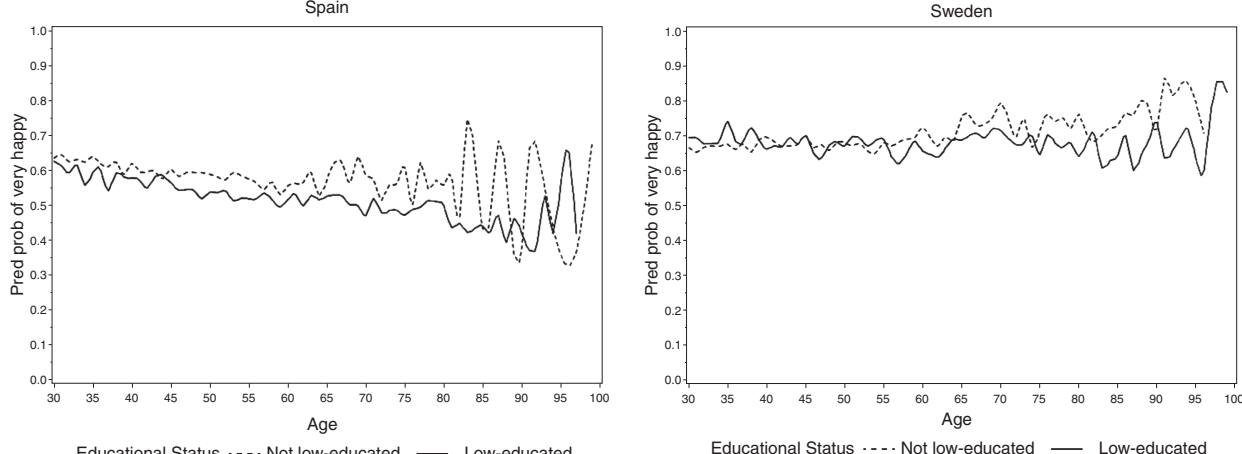

Educational Status . . . . Not low-educated — Low-educated 


\section{Figure A.1:}

(d) Predicted age variations in high level education effects on happiness based on model 3 in ten countries.
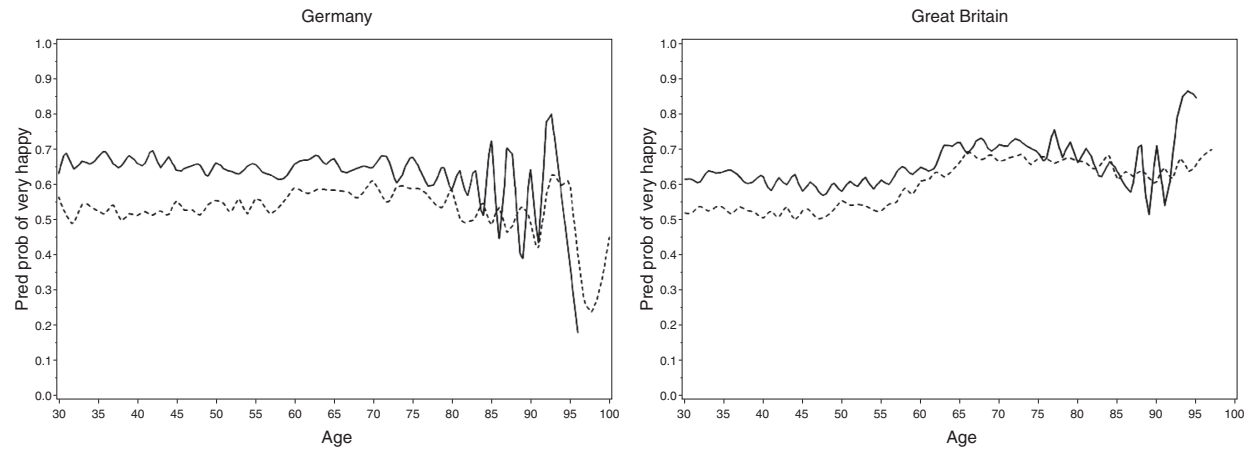

Educational Status . . . . Not high-educated — High-educated Hungary

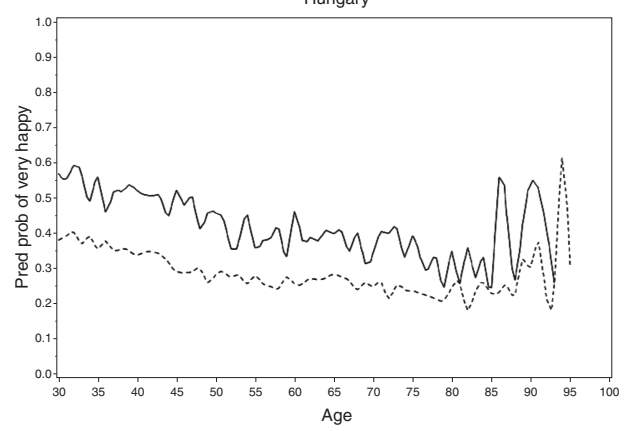

Educational Status . . . . Not high-educated — High-educated

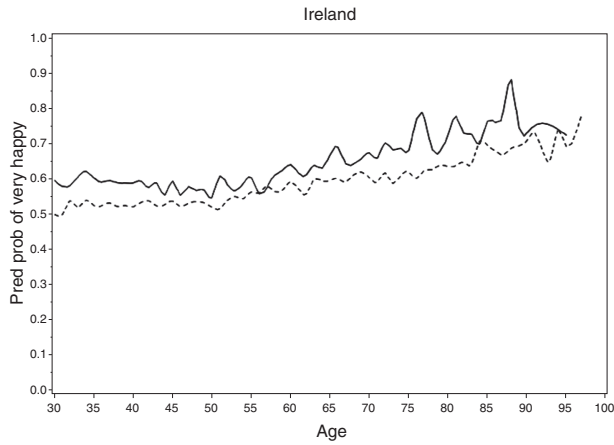

Educational Status . . . . Not high-educated — High-educated

Educational Status .... . Not high-educated — High-educated
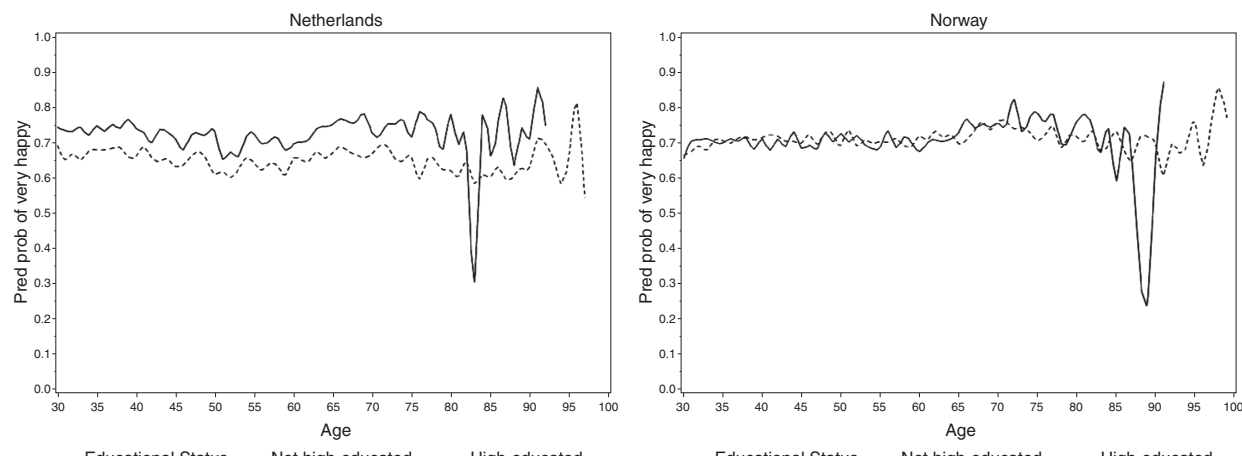

Educational Status .... Not high-educated — High-educated

Educational Status .... Not high-educated — High-educated 


\section{Figure A.1:}

(d) Continued
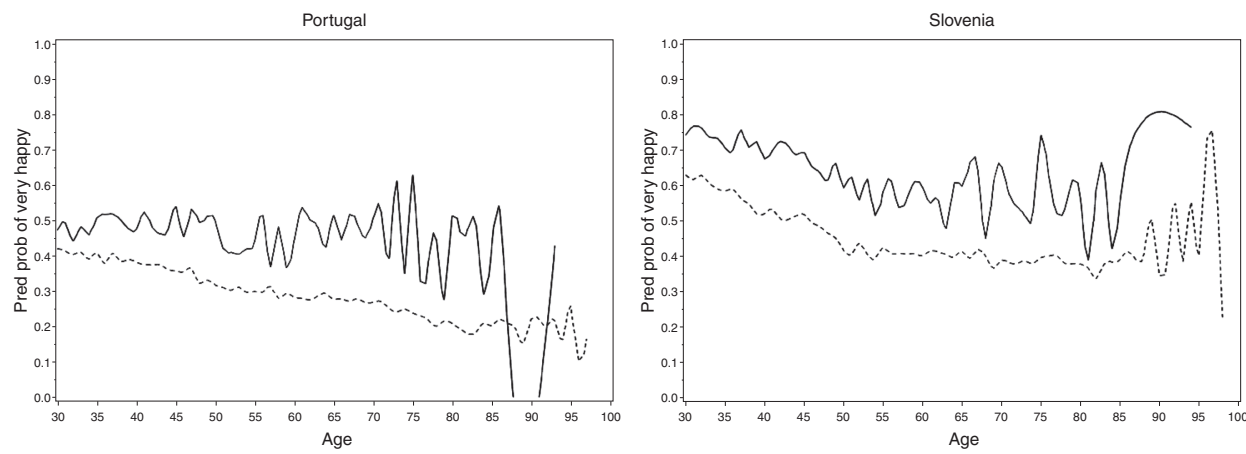

Educational Status - - - Not high-educated — High-educated Spain
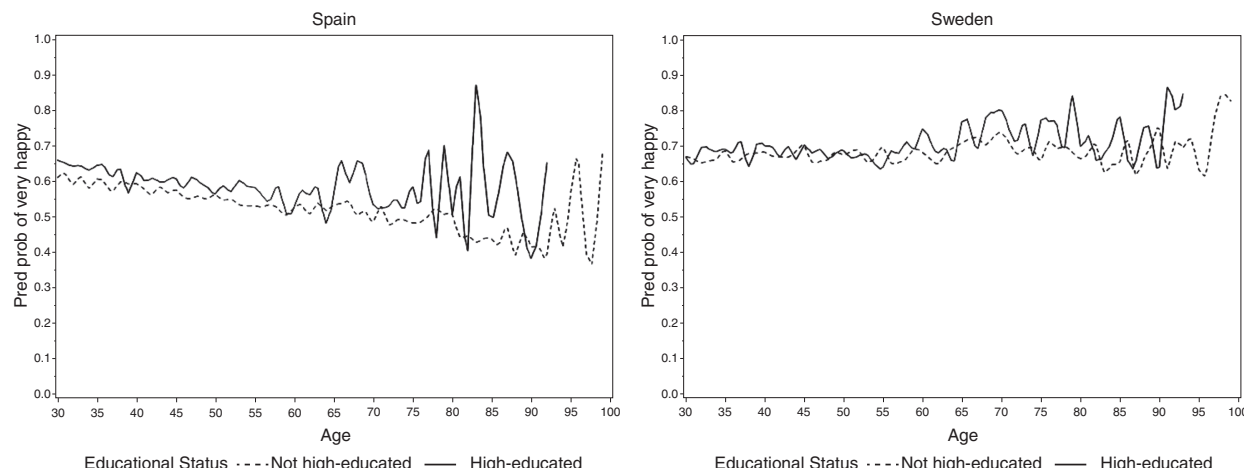

Note: This model includes all independent variables and their interaction effects based on model 3 .

Open Access This article is published under the terms of the Creative Commons Attribution 4.0 International License (https://creativecommons.org/licenses/by/4.0/) that allows the sharing, use and adaptation in any medium, provided that the user gives appropriate credit, provides a link to the license, and indicates if changes were made. 